\title{
OCORRÊNCIA DE AFLATOXINAS EM FARELO DE ALGODÃO (Gossupium hirsutum L.) DA SAFRA DE 1986
}

\author{
CECILIA MARIA RESENDE GONÇALVES \\ Nutricionista
}

Orientador: Prof. Dr. HOMERO FONSECA

\begin{abstract}
Dissertação apresentada à Escola Superior de Agricultura "Luiz de Queiroz", da Universidade de São Paulo, para obtenção do título de Mestre em Agronomia. Área de Concentração: Tecnologia de Alimentos.
\end{abstract}

\author{
PIRACICABA \\ Estado de São Paulo - Brasil \\ Junho - 1987
}


G6350 GONCALVES, Cecilia Maria Resende

coorrência de aflatoxinas em farelo de algodão (Gossupium hirsutum L.) da safra de 1986. Piracicaba, 1987.

$63 \mathrm{p}$.

Diss. (Mestre) - ESAIQ

Bibliografia.

1. Aflatoxina em farelo de algodão. 2. Algodão - Produto derivado. 3. Farelo de algodão - Aflatoxina. I. Escola Superior de Agricultura "Iuiz de Queiroz", Piracicaba. II. TII tulo. 
OCORRENCIA DE AFLATOXINAS EM FARELO DE ALGODÃO

(Gossypium hirsutum L.) DA SAFRA DE 1986

Cecilia Maria Resende Gonçalves

Aprovada em 08.07.1987

Comissão julgadora

Prof. Dr. Homero Fonseca

ESALQ/USP

Prof. Dr. João Nunes Nogueira

ESALQ/USP

Prof. Dr. Luiz Carlos Basso

ESALQ/USP

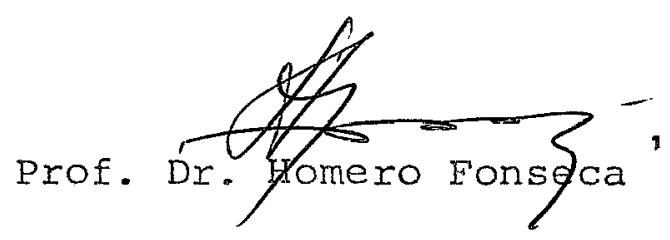


.ii.

Aos meus pais,

Luizinha e Carlos;

aos meus irmãos

Aurea, Tânia, Luiza e Carlos;

aos meus sobrinhos,

Lucas e Daniela,

- DEDICO - 
-iit.

AO Prof. Dr。 HOMERO FONSECA pela orientação segura, confiança e amizade que sempre me dedicou demonsitrando carinho e paciência, sendo um grande exemplo de mestre. 
A amiga ALAIDE HERMINIA DE AGUIAR OLIVEIRA $e$ ao amigo VALDENIR QUEIROZ RIBEIRO, pela relevante contribuição científica indispensáveis à conclusão deste trabalho. 


\section{AGRADECIMERTOS}

- A Fundação Universidade Federal do Piauí, pela oportunidade concedida para a realização do Mestrado em Tecnologia de Alimentos.

- A todos os professores do Departamento de Tecnologia Rural, pela amizade, colaboração e ensinamentos efetivamente prestados.

- Ao Programa de Incentivo à Capacitação de Docentes - MEC, pela bolsa de estudo concedida no decorrer do curso de Mestrado.

- Ao Consèiho Nacional de Desenvolvimento Cientifico e Tecnológico (CNPq) pelo apoio financeiro necessário à realização desta pesquisa.

- Às indústrias de óleo pelo fornecimento do material, sem o qual não seria possível a realização deste trabalho.

- Â Unidade de Execução de Pesquisa de Âmbito Estadual (UEPAE de Teresina)", pertencente à EMBRAPA, pelo apoio e colaboração na análise estatística.

- A equipe da biblioteca do Departamento de Tecnologia Rural pela prestimosidade no atendimento durante as fases de estudo e elaboração do trabaiho.

- A todos os colegas do curso de Pós-Graduação pela convivência e amizade.

- Aos Pesquisadores Humberto de Campos, Antonio Francisco Iemma e Valdenir Queiroz Ribeiro, pela orientação, suges- 
tão e revisão das análises estatísticas.

- A técnica de laboratório Ivani Valarini e ao Sr. João Baptista Beraldo pela colaboração nos trabalhos de laboratório, bem como a todos os funcionários do Departamento de Tecnologia Rural pela boa vontade demonstrada.

- A Maria Antonia Calori pelas sugestões e pelo apoio amigo.

- As amigas Suzana Dellers Ferreira e Marilia Gonçalves Borges Silveira pelas sugestões e revisão do manuscrito.

- A bibliotecária Sônia Corrêa da Rocha pela atenção dedicada à revisão bibliográfica.

- Ao Mestre amigo Paulo Roberto Cantarelii pela ajuda na elaboração do Summary.

- Aos collegas do Departamento de Nutrição da Fundação Universidade Federal do Piauí pela colaboração e confiança demonstrada concedendo-me afastamento para a conclusão do Mestrado.

- A Marcos David Figueiredo de Carvalho que a todo momento acompanhou minhas atividades, pelo apoio constante, carinho e compreensão. 
SURA留 II

Pāgina

LISTA DE TABELAS $\ldots \ldots \ldots \ldots \ldots \ldots \ldots \ldots \ldots \ldots \ldots \ldots \ldots \ldots \ldots \ldots$

RESUMO $\quad \ldots \ldots \ldots \ldots \ldots \ldots \ldots \ldots \ldots \ldots \ldots \ldots \ldots \ldots \ldots \ldots \ldots \ldots \ldots \ldots$

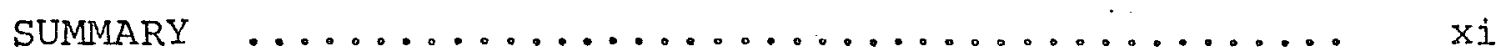

1. INTRODUÇÃO $\ldots \ldots \ldots \ldots \ldots \ldots \ldots \ldots \ldots \ldots \ldots \ldots \ldots \ldots \ldots \ldots$

2. REVISÃo DE LITERATURA $\ldots \ldots \ldots \ldots \ldots \ldots \ldots \ldots \ldots$

3. MATERIAL E METOdOS $\ldots \ldots \ldots \ldots \ldots \ldots \ldots \ldots \ldots \ldots \ldots$

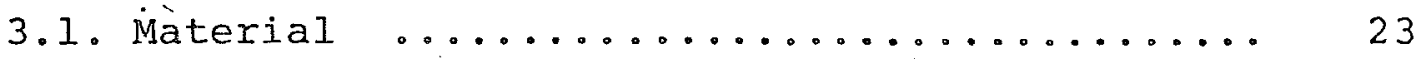

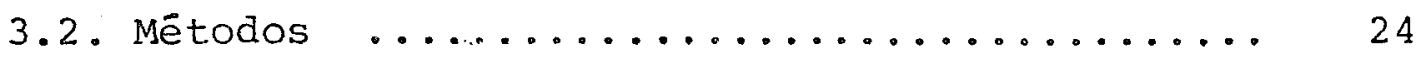

3.2.1. Coleta das amostras $\ldots \ldots \ldots \ldots \ldots \ldots \quad 24$

3.2.2. Preparo das amostras $\ldots \ldots \ldots \ldots \ldots 24$

3.2.3. Determinação das aflatoxinas $\ldots \ldots \ldots 24$

.3.2.3.1. Extração e purificação do extrato $\ldots \ldots \ldots \ldots \ldots \ldots .25$

3.2.3.2. Cromatografia em camada delgada $\ldots \ldots \ldots \ldots \ldots \ldots .26$

3.2.4. Análise estatística $\ldots \ldots \ldots \ldots \ldots 28$

4. RESUltados E DISCUSSÃO $\ldots \ldots \ldots \ldots \ldots \ldots \ldots \ldots$

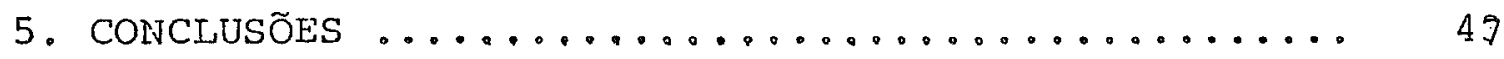

6. REFERENCIAS BIBLIOGRTFICAS $\ldots \ldots \ldots \ldots \ldots \ldots, 48$ 


\section{LISTA DE TARLAS}

Pāgina

1 Conteúdo de aflatoxinas em alimentos animais e percentagens máximas permissiveis de mistura destes componentes em rações, conforme a espé-

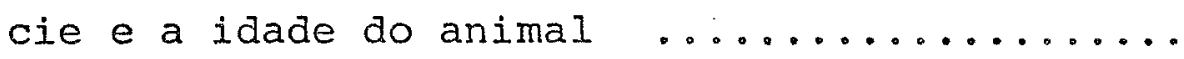

2 Ocorrência de aflatoxina $B_{1}$ (ppb) em farelo de algodão, em diversas épocas, proveniente da empresa "A", Araraquara (SP), Paraguaçu Paulista (SP) 'è Londrina (PR), no ano de 1986 (média semanall $\ldots \ldots \ldots \ldots \ldots \ldots \ldots \ldots \ldots \ldots \ldots \ldots \ldots \ldots \ldots \ldots \ldots$

3 Ocorrência de aflatoxina $B_{I}$ (ppb) em farelo de algodão, em diversas épocas, proveniente da empresa "B", Maringá (PR), no ano de 1986 (mẻdia

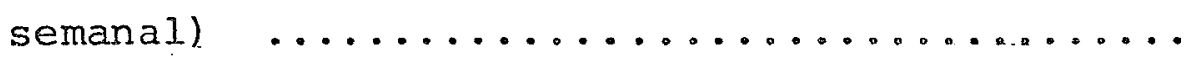

4 Ocorrência de aflatoxina $B_{1}$ (ppb) em farelo de algodão, em diversas épocaś, proveniente da empresa "C", Bauru (SP) e Maringā (PR), no ano de 1986 (média semanal) $\ldots \ldots \ldots \ldots \ldots \ldots$

5 Ocorrência de aflatoxina $B_{I}$ (ppb) em farelo de algođão, em diversas épocas, proveniente da empresa "D" Campinas (SP), no ano de 1986 (mé-

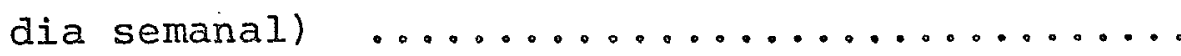


6 Ocorrência de aflatoxina $B_{1}(\mathrm{ppb}$ ) em farelo de algodão, em diversas épocas, proveniente da empresa "E", Guararapes (SP), no ano de 1986 (mëdia semanal) $\ldots \ldots \ldots \ldots \ldots \ldots \ldots \ldots$

7 Variação na incidência de aflatoxina $B_{1}$ (ppb) em farelo de algodão, proveniente de diversas regiões, em função do tempo; no ano de 1986 ...

8 Ocorrência de aflatoxina $B_{1}$ (ppb) em farelo de algodão, proveniente de 5 empresas com 8 indústrias localizadas em 7 regiões e os dados (ordens) apropriados ã aplicação do teste de Kruskal-Wallis, no ano de $1986 \ldots \ldots \ldots \ldots$

9 Diferenças $\left|\bar{R}_{i}-\bar{R}_{j}\right|$ em valores absolutos entre pares de méäias das somas das ordens atribuídas às indústrias na classificação conjunta das 169 amostras de ocorrência de aflatoxina $B_{1}$ (ppb) em farelo de algodão, no ano de $1986 \ldots$... 


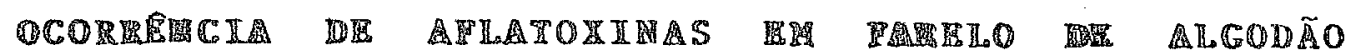

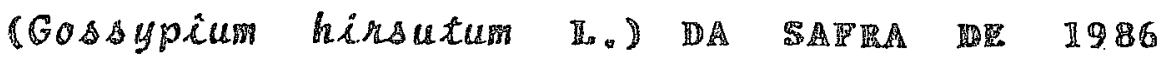

Autora: Cecilia Maria Resende Gonçalves Orientador: Prof. Dr. Homero Fonseca

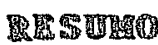

Neste trabalho foram determinados a ocorrência e o nível de contaminação, com aflatoxinas, de 169 amostras de farelo de algodão. As amostras foram fornecidas por indústrias de óleo localizadas nas regiōes de Araraquara, Campinas, Bauru, Paraguaçu Paulista, Guararapes, Londrina e Maringā e foram coletadas nos meses de abril a novembro da safra de 1986. A determinação das aflatoxinas foi feita por cromatografia em camada delgada.

Dos resultados pôde-se concluir que: 1) 114 amostras estavam contaminadas com aflatoxina, representando $67,45 \%$ do total; 2) o nível de contaminação foi baixo, com valores variando de menos de 1.0 a 40 ppb, sendo que as amostras com 40 ppb representaram apenas $12,30 \%$ do total contaminado; 3) houve diferenģa significativa $\cdots(\alpha=0,05)$ entre as diversas rëgiões estudadas, tendo a de Maringá apresentado a maior incidência e os teores mais elevados de aflatoxina $\left.B_{1} ; 4\right)$ as regiões de menor incidência e menor teor de aflatoxina $B_{1}$ foram Araraquara, Campinas e Bauru; 5) não houve predominância da incidência de aflatoxina $B_{I}$ em qualquer época de toda a safra; 6) em todas as amostras investigadas, a inica aflatoxina encontrada foi a $B_{1}$. 


\section{OCCURPENCE OF AFLATIOXINS IN COTTONSEED AEALS \\ (Gossypium hirsutum L.) DURING THE 1986 CROP}

Author: Cecilia Maria Resende Goncalves Adviser: Prof. Dr. Homero Fonseca

\section{SUMMARY}

In the present work the occurrence and the level of aflatoxin contamination in 169 samples of cottonseed meals were investigated. The samples were furnished by oil processing plants located in the regions of Araraquara, Campinas, Bauru, Paraguaçu Paulista, Guararapes, Londrina and Maringá from April to November 1986 and aflatoxin determined by thin layer chromatography.

From the results the following conclusions could be drawn: 1) 114 samples, representing $67.45 \%$, were contaminated with aflatoxin; 2) the level of contamination was considered low with values ranging from 10 to $40 \mathrm{ppb}$. The latter value represented only $12.30 \%$ from the total positive samples; 3$)$ there was a significant difference $(\alpha=0.05)$ among the regions studied having Maringä showed the higher incidence and level of contamination, while Araraquara, Campinas and Bauru lower values; 4) there was no predominance of the aflatoxin incidence any time during the whole processing period; 5) in all investigated samples the sole aflatoxin found was the $\mathrm{B}_{1}$. 


\section{INTSODEG}

As sementes oleaginosas normalmente são boas fontes de proteínas e calorias, e os seus subproảutos tambëm são ricos em proteínas e aminoácicos essenciais, alēm de contribuírem para o conteūdo energētico das rações (TAFURI \& RODRIGUES, 1984)。

O processo de industrializaçāo das sementes oleaginosas produz dois compostos distintos: os óleos vegetais e as tortas ou farelos. As tortas ou farelos, assim chamados segundo o tipo de extração a que foram submetidas as sementes oleaginosas, são, em sua composição, praticamente iguais às sementes originais (ROHR, 1978), porém com teor de öleo baixo na torta ou insignificante no farelo.

O Earelo de algodão, um subproduto de elevado valor nutritivo, contém cerca de 45 a $48 \%$ de proteina, $6,8 \%$ de nitrogênio, 2,9\% de fósforo, menores quantidades de óleo, cálcio, sódio, magnésio, ferro, vitaminas do complexo $B$ e vitamina $C$ (ABRAHÃO et alii, s.d.). Por possuir uma grande quantidade de proteina (TANGO 1965 e 1966) considerada de boa qualidade é muito utilizado como suplemento protéico no balanceamento de rações animais.

Sabe-se que em todo o globo terrestre, sobretudo nos países menos desenvolvidos, onde há uma enorme concentração de pessoas de menor poder açuisitivo, o problema do dēficit calórico-protéico assume proporções alarmantes. E cada 
vez mais problemātico alimentar a população humana, pois o consumo "per capita" de alimentos vem diminuindo, ao mesmo tempo em que a desnutrição dissemina-se como consequência da má distribuição de riquezas, do rãpido crescimento dos povos, da crise na produção de alimentos, entre tantos outros fatores. Uma alternativa para consumo humano é a produção de farinhas de sementes ou de tortas de algodão, atravës da aplicação de processos tecnológicos simples a custos reduzidos.

Diante desse quadro de desnutrição e da grande quantidade excedente de farelo de algodão, que pode ser aproveitado como farinha, no enriquecimento de alimentos básicos destinados ao consumo por parte de grupos de escasso poder de compra e vulnerāveis à desnutrição, hả na atualidade, uma enorme necessidade e um crescente interesse no emprego do farelo de algodäo paIa consumo humano (ELIAS \& BRESSANI, 1969; BUCKLE \& SILVA, 1975; 1ONCADA \& GUTIERREZ; 1979).

Entretanto, muitas vezes a ocorrência de fungos toxigênicos em sementes, tortas e farelos torna-os imprōprios ao preparo de rações destinadas à alimentação animal e tambëm à alimentação humana. o consumo de alimentos que contêm essas toxinas tem provocado efeitos prejudiciais à saúde, pois" promove uma redução na resistência imunológica, possibilitando à instalação de doenças infecciosas nos animais e no homem, ocorrendo, em alguns casos, a morte. Algumas dessas toxinas são ainda cancerígenas e mutagênicas para muitas espécies de animais. Além de prejudicar os animais mais sensiveis, elas podem ser encontradas no leite de vacas alimentadas com farelo tóxico e atingir o homem através do consumo do leite contaminado.

Um dos principais fungos produtores de toxinas cancerígenas é o Aspergillus flavus. Este, em condições favoráveis de temperatura e umidade, produz um conjunto de 
substâncias tóxicas denominadas aflatoxinas. Dentre estas, a que vem despertando maior atenção dos pesquisadores é a aflatoxina $B_{1}$, porque, de um modo geral, seus efeitos são mais importantes, além de ter maior potencial cancerígeno que as demais (CLIFFORD \& REES, 1965; WOGAil, 1966 e 1968; TAI GO, 1974).

A maioria dos trabalhos consultados mostra que, dentre as sementes oleaginosas, o amendoim e seus derivados constituem-se nos produtos mais frequentemente contaminados pelas aflatoxinas. No entanto, sabe-se hoje que essas toxinas, sobretudo a aflatoxina $B_{1}$, vêm sendo detectadas em grande parcela dos gêneros alimentícios consumidos por populações de diferentes regiões (LAPA, 1983).

Em regiões de clima quente e úmido o fungo encontra as condições mais favoráveis ao seu completo desenvolvimento e produção dé aflatoxinas nos alimentos, contaminando-os.

O uso de rações à base de subprodutos de sementes oleaginosas tem como finalidade suplementar a alimentação dos animais e de populações carentes de uma nutrição adequada. Assim, em regiões onde predomina a desnutrição e que apresentam as condições climāticas favoráveis à produção de aflatoxinas, é inútil e até prejudicial complementar a-dieta através de um produto contaminado com tais toxinas.

No Brasil, o problema das aflatoxinas assume um carāter muito sërio porque a secagem e o armazenamento das vagens e amêndoas são feitos em conciç̧ōes inadequadas. Esse problema aumenta consideravelmente diante da constatação de que a ocorrência de aflatoxinas em farelo de algodão não è monitorada no país. Portanto, há um risco para a saüde humana e animal, que estão expostas aos efeitos nocivos ocasionados pelas toxinas. Por isso, é necessärio determinar 
os niveis de aflatoxinas em farelo de algodão, já que este é utilizado na alimentação animal e pode ainda ser empregado na alimentação humana com o fim de contribuir para a meIhoria do estado de nutrição de indivíduos que vivem em cons tante déficit alimentar.

Não tendo sido encontrado na literatura relato de levantamentos ou monitorações em nosso país de ocorrên cia de aflatoxinas em farelo de algodão, decidiu-se efetuar esta pesquisa.

com base nesses antecedentes, este trabalho teve os seguintes objetivos:

1. Determinar a ocorrència e o nivel de contaminação com aflatoxinas do farelo de algodão procedente de indústrias de óleo localizadas em determinadas regiões, durante a safra de 1986;

2. Investigar se haveria variação na incidência e no teor de aflatoxinas ao longo da safra, bem como, se haveria diferença entre as regiões. 


\section{MREISATO DR HTTERATURA}

Os efeitos tóxicos ocasionados pelas aflatoxinas foram observados pela primeira vez por STEVENS et alii (1960) quando descreveram o aparecimento de uma doença, na Inglaterra, que causou a morte de um grande número de peruzinhos. Estas observações foram confirmadas por BLOUNT (1960), MANN (1960), SMITH (1960), SWARBRICK (1960) e WANNOP (1960).

Muitas hipóteses surgiram para tentar explicar a morte dos animais. Enquanto MANN (1960) acreditava ser um cereal o responsāvel pela doença, SMITH (1960) suspeitava que ela deveria ser causada por algum fator nutricional.

Posteriormente, ASPIIN \& CARNAGHAN (1961) verificaram que o envenenamento das aves era causado pela ingestão do farelo de amendoim importado do Brasil. Ao mesmo tempo, CARNAGHAN \& SARGEANT (1961), GRAY (1961) e LOOSMORE \& HARDING (196I) constatavam também a morte de animais que tinham o farelo de amendoim como componente básico da dieta. Logo a seguir, foi sugerido que a torta de amendoim poderia estar contaminada com microrganismos.

SARGEANT et alii (1961), pesquisando os microrganismos presentes na ração dos animais, isolaram e identificaram o fungo Aspergillus flavus Iink ex Fries como sendo o produtor do fator tóxico, denominado de aflatoxina. 
Estudos posteriormente realizados sobre os mëtodos de purificação e de dosagem das toxinas, identificaram dois tipos de aflatoxinas designadas de B ("blue") e G ("green") em função de suas fluorescências azul e verde quando observadas sob luz ultravioleta de $365 \mathrm{~nm}$ (TROPICAL PRODUCTS INSTITUTE, 1962).

HARTLEY et alii (1963) verificaram que as aflatoxinas $B$ e $G$ eram constituídas por quatro frações denominadas: $B_{1}, B_{2}, G_{1}$ e $G_{2}$. Em seguida, ficou demonstrado que essas toxinas normalmente eram produzidas na proporção aproximada de 40:1:50:1, respectivamente (HARTLEY et alii, 1963; CUCULLU et alii, 1966).

Das quatro aflatoxinas principais $\left(B_{1}, B_{2}, G_{1}\right.$ e $G_{2}$ ), a mais tóxica e cancerígena é a $B_{1}$. A forte habilidade de ligação da aflatoxina $B_{1}$ com o ácido desoxiribonucléico (ADN) é o principal aspecto de suas propriedades tóxicas e cancerígenas (SPORN et alii, 1966). Por causa de sua elevada toxicidade, a aflatoxina $B_{I}$ é utilizada para a determinação da toxidez de produtos contaminados com as aflatoxinas (CosTA, 1967). A aflatoxina $G_{1}$ também deve ser considerada quando presente em altas concentrações pois possui aproximadamente a metade da toxidez da aflatoxina $B_{1}$ (NAKAMURA, 1968).

Segundo FRAYSSINET \& LAFARGE (1970), LAFONT (1970) e EDDS (1973), todos os seres vivos são sensiveis, em diferentes graus, à ação da aflatoxina $B_{1} e$ as lesões provocadas por ela podem ser de dois tipos: agudas, ocasionadas pela ingestão de doses relativamente elevadas, provocando lesões hepáticas graves e de efeito quase sempre letal; crônicas, produzindo lesões progressivas, severa depressão do crescimento corporal, alterações histológicas e hepatomas, após um pexíodo mais ou menos prolongado de ingestão de doses subagudas. 
Foi constatada a existência de outras toxinas denominadas $M_{1}$ e $M_{2}$ no lette, na urina e nas fezes de animais alimentados com tortas e farelos tóxicos (DE IONGH et alii, 1964; ALLCROFT et alli, 1966). Estas substâncias apresentam praticamente a mesma toxicidade das aflatoxinas $B_{1}$ e $\mathrm{B}_{2}$, respectivamente. Outros metabólitos, $\mathrm{B}_{2 \mathrm{a}}$ e $\mathrm{G}_{2 \mathrm{a}}$, com toxidez 60 a 100 vezes inferior à das aflatoxinas $B_{1}$ e $G_{1}$, também foram isolados e identificados (DUTTON \& HEATHCOTE, 1966).

CLEGG \& BRYSON (1962), ALLCROFT \& IEWIS (1963), NEWBERNE (1973) e PIER (1973) verificaram que muitas espécies de animais são sensĩveis à ação das aflatoxinas e os efeitos crônicos ocasionados pela ingestão dessas substâncias são: hemorragia, cirrose, necrose e cāncer no fígado, seu principal órgão de ação. Além disso, os animais podem diminuir seu ganho de peso e seu desempenho geral devido a redução de sua resistência imunológica, diretamente proporcional à quantidade e/ou ao período de ingestão das aflatoxinas, podendo em muitos casos, morrer ou serem acometidos por várias doenças secundärias (ALLCROFT \& LEWIS, 1963; MUSTAKAS et alii, 1964; WOGAN, 1968; FONSECA, 1968 e 1969). As toxinas podem alojar-se nos tecidos e órgãos dos animais e tambëm estar presentes em alimentos que são consumidos pelo homem, como leite, queijo, ovos e produtos cärneos, entre outros (WESSEL \& STOLOFF, 1973).

Ainda com relação à suscetibiliảade dos animais, sabe-se que a mesma varia conforme a espécie, havendo algumas que são totalmente resistentes, como o camundongo (PLATONOW, 1964) e o carneiro (NEWBERNE, 1973), enquanto que, dentro de uma mesma espēcie, os mais jovens são mais sensiveis (ALLCROFT \& LEWIS, 1963). Dentre as espécies mais sensĩveis estão os ratos (LANCASTER et alii, 1961) e as trutas (NEWBERNE), 1973)。 
Com relação à ação das aflatoxinas sobre o homem, vários autores consideram a hipōtese dessas micotoxinas serem cancerígenas, mostrando gue há uma correlação altamente positiva entre a quantidade de aflatoxinas ingeridas e a incidência de câncer primärio no fígado, em países onde a população frequentemente consome alimentos mofados. Além do câncer, as aflatoxinas pođem ocasionar o surgimento de outras graves doenças, como a encefalopatia e degeneração goraa das vísceras (EDFV - Encephalopathy and Fatty Degeneration of the Viscera), a hepatite infecciosa do virus B e o "kwashiorkor" (DAVIDSON, 1970; EDDS, 1973; CAMPBELI \& STOLOFF, 1974; HENDRICKSE et alii, 1982; FONSECA, 1983; ORGANIZACION PANAMERICANA DE LA SALUD, 1983; FONSECA, 1984).

Alguns estudos sugerem a possibilidade de que as aflatoxinas sejam responsäveis por hepatopatias, encontradas com frequência em habitantes de determinadas regiões da Africa, onde predomina a deficiência de proteínas (BANKS JUNIOR et alii, 1964; ALBERT \& DAVIDSON, 1969).

Até o momento, as aflatoxinas continuam sendo consideradas como um dos mais potentes agentes químicos cancerígenos jä conhecidos.

O nível de 30 ppb das aflatoxinas $\left(B_{1}+G_{1}\right)$ é - Iimite mâximo permitido em alimentos destinados ao consumo humano, segundo as normas brasileiras (FONSECA, 1983). Em outros paises esse valor varia entre zero e 50 ppb (CAMARGO, 1986).

O fungo Aspergillus flavus è encontrado normalmente no ar, no solo, nas plantas e nos animais (TANGO, 1974; CARVALHO \& CHALFOUN, 1984). Entretanto, CARVALHO \& CHALFOUN (1984) observaram que sua ocorrência em solos de regiões tropicais é muito maior do que nos de regiões temperadas, e sua inciância pode ser facilmente reconhecida pela 
coloração verde-amarelada e pelo aspecto floculado que apresenta.

HESSELTINE et alii (1966), analisando o comportamento do Aspergillus flavus quanto à sua capacidade de produzir aflatoxinas, observaram que nem todas as cepas são capazes de produzi-la. Outros fungos, como por exemplo, - Aspergillus parasiticus tambēm produzem aflatoxinas.

Segundo SCHINDLER et alii (1967), SCHROEDER \& HEIN JUNIOR (1968), NORTHOLT \& BULLERMAN (1982) e ORGANIZACION PANAMERICANA DE LA SALUD (1983) as aflatoxinas podem ser produzidas em qualquer tipo de alimento e de rações. desde que as condições favoräveis de temperatura e umidade, principais fatores que regulam o crescimento do fungo e a produção de toxinas, estejam presentes. De uma maneira geral, a atividade de āgua mínima em alimentos necessário ao crescimento do Aspergillus flavus e à produção de aflatoxinas está em torno de 0,85 (SANDERS et alii, 1968; ORGANIZACION PANAMERICANA DE LA SALUD, 1983). A faixa de temperatura para que o fungo possa crescer situa-se num intervalo de 10 a 409C, sendo a temperatura ótima aproximadamente $25 \% \mathrm{C}$ (FONSECA, 1984).

. RICHMOND et alii (1.962a e 1962b) estudando a toxigenicidade do Aspergillus flavus verificaram que o crescimento do fungo e a produção de aflatoxinas podem ocorrer em rações que não contēm amendoim. A doença também se reproduziu em animais quando alimentados com soja, feijão, semente de algodão e trigo contaminados com o Aspergillus flavus. Mais tarde, GIBSON (1962) constatou a presença de aflatoxinas em milho e LOOSMORE et alii (1964) obtiveram semelhante resultado em torta de algodão, onde encontraram níveis considerados tóxicos ce aflatoxina $B_{I}$.

Embora o amencioim seja o substrato preferido 
pelo Aspergillus flavus, no estudo realizado por sinnhuber et alii*, citados por SALUNKE et alii (1982) foi observado o aparecimento de hepatomas em trutas alimentadas com farelo de algodão. Alēm disso, a descoberta de altos teores de aflatoxinas em sementes e farelos de algodão serve para demonstrar a falta de especificidade do Aspergillus flavus para o substrato no qual cresce (SGARBIERI, 1969).

$$
\text { COSTA (1967), TANGO (1974), STOLOFF (1980), }
$$

MALOZZI (1984) e FARAG et alii (1986) tambêm encontraram cepas aflatoxigênicas em sementes e tortas de algodão, entre outros produtos.

SCHNEIDER et alii (1972) estudaram a ocorrência de aflatoxinas em 99 amostras de sementes de algodão durante os meses de abril a novembro de 1971, em diversas regiöes dạ. Amërica Central. Os resultados obtidos demonstraram a presença de aflatoxinas em 4 amostras, o que representou uma incidência de $4 \%$ do total. A aflatoxina $B_{1}$ foi a ünica encontrada em todas as amostras contaminadas, enquanto a $\mathrm{B}_{2}$. esteve presente em 2 amostras e a $\mathrm{G}_{1}$ foi identificada em apenas uma amostra. Baseados neste comportamento, poNs JUNIOR et alii (1980) investigaram as toxinas que mais ocorrem em sementes de algodão. Os autores observaram as aflatoxinas $B_{1}$ e $B_{2}$ com maior freqtëncia do que as demais.

MAYNE et alii (1966) cinama a atenção pa ra o fato de que o gossipol, pigmento polifenólico encontrado naturalmente na semente de algodão em proporções

* SINNHUBER, R.O.; WALES, J.H.; ENGEETBRECHT, R.H.; AMEND, D.E.; AYRES, J.L.; ASHTON, W.F.; KRAY, W. Aflatoxins in cottonseed meal and heptoma rainbow trout. Federation Proceedings, Wasinington, 24: $267,1965$. 
que variam de 0,4 a $1,5 \%$ de seu peso, provavelmente pode modificar a produção de aflatoxinas pelo Aspergillus blavus.

Segundo MAYNE et alii (1966), GOLDBLATT (1971) e ORGANIZACION PANAMERICANA DE LA SALUD (1983) as aflatoxinas $B_{1}, B_{2}, G_{1}$ e $G_{2}$ podem ocorrer simultaneamente ou não, sendo que suas presenças e concentraçōes variam em função da capacidade genética da cepa produtora, do tipo de substrato em que o fungo cresce e dos fatores ambientais. Todos concordam que as modificações que ocorrem no teor e no tipo de aflatoxina presente na semente de algodão se devem mais às caracteristicas individuais da linhagem do fungo do que ao efeito inibitório dos constituintes da semente.

ENGEBRECHT et alii (1965) examinaram 8 amostras de farelo de algodão e encontraram aflatoxina $B_{1}$ em 4 amostras, tendo determinado nelas valores que variaram entre 19 e $186 \mathrm{ppb}$.

Em trabalhos realizados por Pons Junior et alii*, citados por MAYNE et alii (1966), foram identificadas as aflatoxinas $B_{1}, B_{2}, G_{1}$ e $G_{2}$ em torta de algodão. Por outro lado, MAYNE et alii (1966), realizando o mesmo estudo encontraram com maior freqtência as aflatoxinas $B_{1}$ e $B_{2}$, em sementes e farelo de algodão. Sugerem, ainda, estes autores que as aflatoxinas $G_{1}$ e $G_{2}$ normalmente não estão presentes em sementes de algodão. Resultados similares foram obtidos com as pesquisas de PONS JUNIOR et alii (1968 e 1980) e com os trabalhos de CUCULLU et alii (1972), que comprovaram não ser comum a ocorrência de aflatoxinas $G_{1}$ e $G_{2}$ em sementes e farelo de algodão.

*PONS JUNIOR, W.A.; HOFFPAUIR, C.L.; HOPPER, T.H. Journal of the American Oil Chemists' Society, Chicago, 42: 471-5, 1965. 
MCMEANS et alid (1968) estudaram a ocorréncia de aflatoxinas em farelo de algodão e verificaram que elas podem estar presentes ou nāo no farelo obtido de caroços contaminados. Estes autores demonstraram que havia amostras de caroço de algodão sem aflatoxinas, mas cujo farelo estava infectado. A situação inversa também foi observada. Muitos trabalhos foram feitos para avaliar esse fenômeno, e os resultados indicam que as aflatoxinas ficam concentradas em poucas sementes de um dado lote. Como por exemplo, pode-se citar o trabalho de WHITTEN \& SMITH (1972), no qual amostras de caroço de algodão continham, em média, 8000 ppb de aflatoxina $\mathrm{B}_{1}$. De um lote de 150 sementes, só 18 estavam contaminadas com a toxina, e em apenas uma semente foram encontrados $600.000 \mathrm{ppb}$ de aflatoxina $\mathrm{B}_{1}$. Por causa do acúmulo de aflatoxina em nîveis elevados em alguns grãos, vários estudos foram feitos para tentar descobrir mëtodos que permitam separar os caroços de algodão contaminados com aflatoxinas antes do processamento para que se consiga uma torta isenta de contaminação. Os métodos de remoção física usados são relacionados com o peso, o tamanho, ou a cor da semente ou da fibra. Entretanto, nenhuma dessas características parece ser um bom indicativo do teor de aflatoxinas em sementes de algodão (KOLTUN et alii, 1974).

Um sinal característico da infecção pelo Aspergillus flavus é a presença de um brilho fluorescente amarelo-esverdeado na fibra ou na semente de algodão quanòo observados sob luz ultravioleta (BOLLENBACHER \& MARSH, 1954; ASHWORTH JUNIOR et alii, 1968; HAMSA \& AYRES, 1977). Esta fluorescência, denominada de BGYF (bright greenish-yellow fluorescence) ou fluorescência "cateye" ("olho de gato") parece ser um forte indicativo da presença do Aspergillus flavus e das aflatoxinas em sementes e fibras de algodão (KOLTUN et alii, 1974; LEE \& RUSSELI, 1981; LEE et alii, 1986). 
ASHWORTH JUNIOR \& MCMEANS (1966), pesquisando - teor de aflatoxinas nas sementes, verificaram que nem sempre há uma relação entre o aparecimento da fluorescência BGYF no caroço e na fibra de algodão e a presença de aflatoxinas, ou seja, é possível existir fibras ou caroços infectados mas que não manifestam a fluorescência BGYF sob luz ultravioleta. Da mesma forma, podem existir amostras fluorescentes sem estarem contaminadas.

Baseados no comportamento fluorescente das fibras e caroços de algodão, GOLDBLATT (1971), LEE \& CUCULLU (1978), LEE \& RUSSELL (1981) e LEE et alii (1986) investigaram também a relação desse fenōmeno com a presença do Aspergillus flavus. Os autores observaram uma alta correlação entre a fluorescência amarelo-esverdeada, sob luz ultravioleta, de sementes de algodão comprometidas, com seus conteūdos de aflatoxinas.

Entretanto, ASHWORTH JUNIOR et alii (1968), mesmo sabendo que o método de triagem de caroços de algodão infectados com base nas suas características fluorescentes não é $100 \%$ eficiente, propuseram um, equipamento para separação eletrônica das sementes fluorescentes cas não fluorescentes.

No processo de seleção das sementes de algodão, além da fluorescência BGYF, outras características também devem ser observadas, como ausência de linter em alguns pontos da semente, que pode ocorrer devido à invasão de fungos, caroços com linter delgado e amarelado e sementes quebradas.

As caracteristicas de densidade das sementes de algodão têm sido também usadas para discriminar as sementes contaminadas das não contaminadas através da utilização de um aparelho de projeção. As sementes sadias e maduras são 
projetadas a uma maior distância que as sementes contaminadas devido à sua maior densidade. Em testes iniciais, sementes de algodão contendo de 40 a 80 ppb de aflatoxina $B_{1}$ apresentaram mais de $63 \%$ da toxina concentrada em 68 das sementes, enquanto que $85 \%$ da toxina $B_{I}$ poderia ser obtida ảe $25 \%$ das sementes, conforme citado por GOLDBLATT (1971). Outros testes, posteriormente desenvolvidos empregando esta técnica, indicaram que este mëtodo é inconsistente.

O principal problema de contaminação da cultura do algodão resulta da infecção das sementes que ocorre no campo (ASHWORTH JUNIOR \& MCMEANS, 1966; WIDSTROM, 1979; KLICH \& LEE, 1982). Entretanto, se a contaminação pelo Aspergillus flavus e a subseqthente produção de toxinas não ocorrer no campo, antes da colheita, ela poderá ocorrer no período pós-colheita, durante o armazenamento, o transporte ou o processamento (HAMSA \& AYRES, 1977).

Dentre os fungos que podem aparecer no campo, - Aspergillus blavus é o mais importante (ASHWORTH JUNIOR et alii, 1971a). Este microrganismo, embora predominantemente considerado um fungo de armazenamento (GOLDBLATT, 1971; HAMSA \& AYRES, 1977), tem a capaciäade de invadir o linter, a casca da semente e o embrião no campo, antes mesmo de ser realizada a collheita do algodão (MCMEANS et alii, 1968; ASHWORTH JUNIOR et alii, 1969b e 197la).

Quando o fungo penetra no capulho, ele passa a se desenvolver, e o ideal para ele é que não ocorram lesões que exponham as fibras e as sementes à aeração, pois isso provocaria uma secagem e a não formação de toxinas, o que acontece quando $90 \%$ do capulho está aberto (ASHWORTH JUNIOR et alii, 1969a; RUSSELL et alii, 1976).

- Iínter do caroço de algodão è um substrato pobre para o crescimento do Aspergillus blavus mas, após a 
penetração do micēlio na casca da semente, o crescimento do fungo é rápido (TANGO, 1974).

Os conidios, quando entxam em contato com o caroço de algodão, encontrando condições favoráveis, germinam e invadem o embrião das sementes (HAMSA \& AYRES, 1977). O fungo, após estabilizar-se na semente, cresce dentro das cavidades por onde penetrou e esporula intensamente. o micélio (tecido vegetativo) cresce entre a casca da semente e o embrião e, por isso, caroços aparentemente sadios, ou seja, com a superfície sem apresentar sinais vísiveis de crescimento de fungos, não estão necessariamente isentos de toxinas (CUCCULU et alii, 1966; LEE et alii, 1967; FONSECA, 1984).

A invasão da semente pelo fungo pode acontecer em decorrência de alguns fatores, como condições aỏequadas de temperatura e umidade, danos mecânicos que ocorrem na casca da semente durante a secagem e/ou desfibramento, e orifícios ocasionados por insetos (HAMSA \& AYRES, 1977).

Os insetos são veículos de esporos do Aspergillus blavus e podem levar o fungo diretamente para a semente (RUSSELL et alii, 1976). A lagarta rosada (Peciinophora gossypiela), uma das principais pragas do algodoeiro, é responsabilizáda como um agente que facilita a entrada do fungo pelo seu buraco de emergência na superficie do capulho (BRAZZEL, 1955; LUKEFAHR \& MARTIN, 1963; ASHWORTH JUNIOR et alii, 197la e 1971b; KIYOMOTO \& ASHWORTH JUNIOR, 1974; MCMEANS \& BROWN, 1975; HAMSA \& AYRES, 1977). Da mesma forma que a lagarta rosada, o bicudo do algodoeiro (Anthonomus grandisl também é um importante disseminador do fungo (WIDSTROM, 1979).

Muito embora os danos causados pelos insetos no campo, antes da colheita, sejam os principais responsáveis pela infecção de origem füngica no algodão (LEE et 
alii, 1986), qualquer ciano provocado em um capulho sadio, durante a colheita e a operação de secagem, poderá se transformar em uma via de acesso ao fungo (FONSECA, 1984). Não menos importante do que as lesões provocadas nos capulhos é a perfeita secagem que deve seguir-se à colheita. Para uma maior segurança contra a infecção funngica, a secagem deve ser rápida e eficiente, pois se isto não ocorrer o risco de contaminação será muito grande.

o teor de umidade da semente de algodão em equilíbrio com a umidade relativa do ambiente é, fundamentalmente, um fator limitante para que aconteça ou não a contaminação. Caroços de algodão com 15,18 e $22 \%$ de umidade, colocaảos sob temperaturas de 27 a 29\%C, têm grandes possibilidades de serem infectados. A variação do conteúdo de umidade de sementes estocadas de 15,1 para 21,8\% de umidade, é suficiente para aumentar em 10 vezes o teor de aflatoxinas. A presença de apenas alguns caroços úmidos no meio da massa armazenada pode fomentar focos de infecção (WHITTEN \& SMITH, 1972)。

A umidade ideal para estocar o caroço de algodão está entre 9 e 10\%. Com esses teores de umidade, a semente de algodão, mesmo contaminada, pode ser armazenada por váxios méses sem aumento do teor de toxinas nas sementes (ASHWORTH JUNIOR et alii, 1971a; WHITTEN \& SMITH, 1972). Caroços armazenados com um teor de umidade inferior a 11\%, com certeza terão assegurado a manutenção da sua qualidade durante o armazenamento. O valor critico de umidade situa-se ao redor de 13\%, acima do qual a deterioração é muito rápida (ABRAHÃO et alii, s.a.).

Para CHRISTENSEN (1957), em sementes com cerca de $15 \%$ de umidade jā há limitação do crescimento do Aspergillus flavus. 
MATTIL et alii (1964), em suas pesquisas, demonstraram que na semente de algodão o aumento cio teor de umidade de 14 para 158 propicia a atividade enzimática do gräo, enquanto teores mais elevados favorecem o desenvolvimento de microrganismos. Esses altos teores de umidade da semente decorrem de uma elevada taxa de umidade relativa do ar, em geral superior a 75\%, e nestas condições algumas linhagens do Aspergillus flavus já começam a se desenvolver sobre as sementes.

No farelo de algodäo, o nível critico de umidade está em torno de 10\%. Acima desse valor, os fungos podem se desenvolver e produzir suas toxinas (FONSECA, s.d.). Para que o farelo de algodão possa conservar-se bem, deve ser aconảicionado e armazenado sob condições de baixa umidade a fim ảe não permitir o desenvolvimento de fungos e a produção de toxinas que possam vir a comprometer a qualidade do produto.

WESSELL \& STOLOFF (1973) e RUSSEIL et alii (1976), es tudando o problema de elevada umidade em torno do capulho, verificaram que o efeito da umidade combinado com os danos internos causados pelas lagartas, dificultam a soltura das fibras e a secagem. Nestas condições, a abertura do capulho é lenta e tardia, as sementes demoram para secar, e neste ambiente o fungo encontra condições ideais para seu desenvolvimentó e produção de aflatoxinas.

A temperatura é também um fator importante para o fungo penetrar no capulho. O Aspergillus flavus requer altas temperaturas, na faixa de 28 a $37 \% \mathrm{C}$, para se desenvolver no caroço de algodão (HAMSA \& AYRES, 1977). A faixa ótima de temperatura para produção de aflatoxinas fica em torno de 20 a 259C (SCHINDLER et alii, 1966; ASHWORTH JUNIOR et alii, 1969a; WHITTEN \& SMTTH, 1972; RUSSELL et alii, 1976). 
A invasão da semente de algodão pelo Aspergillus flavus e a produção de aflatoxinas são tambêm influenciadas por, uma enorme gama de microrganismos habitantes das sementes antes da colheita e durante o armazenamento. Outros fungos e bactērias podem ser antagónicos ao Aspergillus flavus ou podem competir com ele na invasão da semente (HAMSA \& AYRES, 1977; NORTHOLT \& BULLERMAN, 1982). Além disso, as sementes de algodão não são consideradas como um substrato inerte à penetração do fungo. As sementes podem ter mecanismos de defesa para impedir que os microrganismos penetrem através de suas aberturas naturais, estratagemas estes que podem ser responsáveis pela resistência de espécies ou variedades. A semente de algodão pode excretar certas substâncias antimicrobianas cuja produção é induzida pelas fitoalexinas (hormónio vegetal) e que apresentam efeitos negativos sobre o fungo invasor (HAMSA \& AYRES, 1977).

FRANK (1978), determinando a ocorrência de aflatoxinas em torta e farelo de algodão, verificou que pode haver um índice de contaminação de até 56\%, cujo valor é variável em função das condições climâticas:

Nos Estados Unidos, a ocorrência de aflatoxinas em sementes e farelos de algodão é bastante elevada (MYCoToxINS and food safety, 1986). Na Califórnia, por exemplo, altas concentrações de aflatoxinas, de $1735 \mu \mathrm{g} / \mathrm{kg}$ a $2578 \mu \mathrm{g} / \mathrm{kg}$, já foram encontradas em semente de algodão (ORGANIZACION PANAMERICANA DE LA SALUD, 1983). Entretanto, a ocorrência ou não de infecção parece estar intimamente relacionada com as condições climáticas da região e/ou do ano agrícola (RUSSELl et alii, 1976). No sudeste, onde ocorrem altas temperaturas, baixa precipitação e lavouras irrigadas, a contaminação do algodão com as aflatoxinas provoca um grande prejuízo (MARSH et alii, 1973; WESSELL \& STOLOFF, 1973; VELASCO et alii, 1975; RUSSELL et alii, 1976; HAMSA \& 
AYRES, 1977; RUSSELL \& IEE;, 1985; LEL et alii, 1986). Por outro lado, na Região Leste ocorre alta precipitação e umidade, mas a temperatura ê baixa, e isto diminui a incidência de aflatoxinas na cultura do algodão (HAMSA \& AYRES, 1977; RUSSELL \& LEE, 1985; LEE et alii, 1986).

Historicamente, chove muito na maioria das regiões brasileiras nos meses de janeiro e fevereiro, quando as temperaturas são altas e a umidade do ar elevada. A partir de março, hā um decréscimo na temperatura e na precipitação pluviomētrica, mas eventualmente chove. Se a colheita do algodão coincidir com o periodo chuvoso, a abertura do capulho será lenta e as sementes irão demorar mais tempo para secar no campo. Nestas condições, a umidade do ambiente e do capulho é elevada ficando propício ao desenvolvimento do fungo e à produção de aflatoxinas (ABRAHÃO*).

MCMEANS \& ASHWORTH JUNIOR (1966) e ASHWORTH JUNIOR et alii (1971a) verificaram que as infecçöes füngicas e as contaminações com aflatoxinas acontecem, essencialmente, no terço inferior da planta do algodão, onde se localiza cerca de $40 \%$ do produto da safra.

Os prejuízos que fungos como o Aspergillus flavus e suas"toxinas podem ocasionar à cultura do algodão são imensos. Dentre eles, destacam-se a descoloração e o apodrecimento de capulhos no campo, diminuindo a sua produtividade (BOLLENBACHER \& MARSH, 1954; CHRISTENSEN, 1957; MARSH \& TAYLOR, 1958; ASHWORTH JUNIOR et alii, 1969a), a queda de preços dos caroços contaminados causada pela redução da qualidade e aceitabilidade das sementes (CHRISTENSEN,

*ABRAHÃO, J. T. M. (Escola Superior de Agricultura "Luiz de Queiroz", ESALQ/USP) Comunicação pessoal, 1987. 
1957 e ASHWORTH JUNIOR et alii, 1968), e a infecção em si que pode passar para a torta ou farelo, causando graves problemas para a saüde humana e animal.

Outro prejuizo importante ocasionado pelas aflatoxinas aparece sobre a viabilidade da semente de algodão. KLICH \& LEE (1982), estuảando a germinação de sementes contaminadas com aflatoxinas, verificaram que apenas $38 \%$ das sementes germinaram normalmente. A taxa de germinação para sementes não infectadas, sob as mesmas condições das sementes contaminadas, é estimada em $90 \%$.

- farelo de algodão é utilizado principalmente na composição de rações animais. Dependendo co teor de aflatoxina presente, hā restrições na percentagem em que ele pode entrar na mistura. De acordo com estudos realizados foi elaborada, uma tabela de uso, de materias-primas contaminadas, na composição de rações destinadas a várias espécies animais (Tabela 1) (FAO, 1979).

TABELA 1 - Conteüdo de aflatoxinas em alimentos animais e percentagens mäximas permissiveis de mistura destes componentes em raçōes, conforme a espécie e a idade do animal.

\begin{tabular}{llll}
\hline $\begin{array}{l}\text { Conteúdo de } \\
\text { aflatoxina } \\
\text { no alimento }\end{array}$ & Tipo de ração & $\begin{array}{l}\text { Máximo } \\
\text { permissivel } \\
\text { de mistura }\end{array}$ & $\begin{array}{l}\text { Conteúdo mäximo } \\
\text { total de aflato- } \\
\text { xina por kg de } \\
\text { ração oronta }\end{array}$ \\
\hline Ligeiramente & patos e marrecos & zero & zero \\
positivo (até & peruzinhos & zero & zero \\
$0,1 \mathrm{mg} / \mathrm{kg}$, ou & pintinhos & zero & zero \\
seja, $100 \mathrm{ppb})$ & Eranguinhos & zero & zero \\
& porcos em crescimento & zero & zero \\
& carneiros em crescimento zero & zero \\
& novilhos & zero & zero
\end{tabular}


TABELA 1 - Conteüdo de aflatoxinas em alimentos animais e percentagens mäximas permissiveis de mistura destes componentes em raçōes, conforme a espécie e a idace do animal.

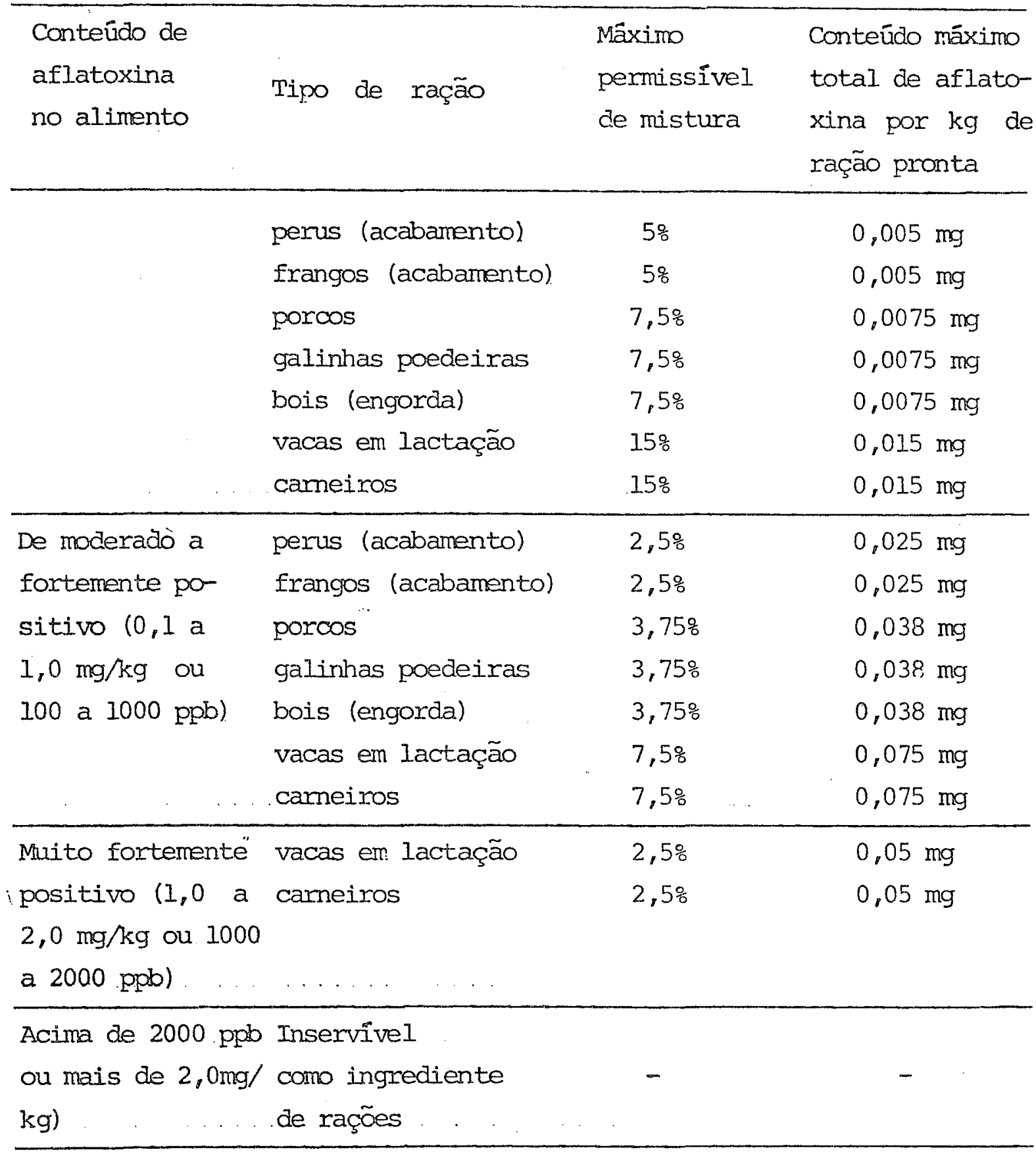

Fonte: FAO (1979) 
- farelo de algodão, a ser empregado na alimentação humana, deve ser produzido por meio de processos tecnológicos especiais para que a remoção e/ou inativação do gossipol ocorra com eficiência (FONSECA, s.d.). Esta substância é um alcalóide, e como tal é tóxico para o homem e para certas espécies de animais. Em geral, o boi e o carneiro não são afetados, porém coelhos e porcos morrem se forem frequentemente alimentados com tortas ou farelos contendo altas taxas de gossipol (FONSECA, s.d.; TANGO, 1973; BRESSANI et alii, 1975).

Antes de ser empregado para complementar a alimentação animal ou humana, o farelo de algodão, deve ser analisado não só para verificar a presença do gossipol, como tambëm, se há contạinação com aflatoxinas. 


\section{MATERIAL B METODOS}

\subsection{Material}

Para este trabalho foram utilizadas 169 amostras de farelo de algodão, do ano agrícola de 1986, fornecidas por 5 empresas que possuem ināústrias de óleo situadas em algumas regiões dos Estaōos de são Paulo e do Paraná, conforme indicadas a seguir:

$$
\begin{aligned}
\text { Empresa "A" - } & \text { com indústrias localizadas em } \\
& \text { Araraquara (SP), Paraguaçu Pau- } \\
& \text { lista (SP) e Londrina (PR); } \\
\text { Empresa "B" - } & \text { com indústria localizada em Ma- } \\
& \text { ringá (PR); } \\
\text { Empresa "C" - } & \text { com indústrias localizadas em } \\
& \text { Bauru (SP) e Maringá (PR); } \\
\text { Empresa "D" - } & \text { com indústria localizada em } \\
& \text { Campinas (SP); } \\
\text { Empresa "E" - } & \text { com indústria localizada em } \\
& \text { Guararapes (SP). }
\end{aligned}
$$


3.2. Métodos

\subsubsection{Coleta das amostras}

As coletas foram realizadas semanalmente, de abril a novembro e de cada indústria era retirada uma amostra de aproximadamente $1,5 \mathrm{~kg}$, em porções diárias de 200 a $300 \mathrm{~g}$, para se ter um material representativo de todos os dias. Após a coleta, as amostras eram identificadas com letras A, B, C, D e E e numeradas em ordem cronológica de acorảo com a semana e a procedência.

\subsubsection{Preparo das amostras}

As amostras de farelo de algodão foram trituradas 3 vezes em moinho de discos (Disc Mill, modelo 4E, The Straub Co, Philadelphia, EUA). Apōs serem misturadas em homogeneizador, as amostras foram guardadas em sacos plásticos e lacradas até serem executadas as análises.

\subsection{3: Determinação das aflatoxinas}

A extração das aflatoxinas do farelo de algodão foi efetuada pelo método de PONS JUNIOR et alii (1966) modificado, seguido de determinação quantitativa por cromatografia em camada delgada em placas de silicagel-G sob luz ultravioleta de $365 \mathrm{~nm}$, pelo mētodo de COOMES \& FEUELL (1965), conforme descrito a seguir. 
3.2.3.1. Extração e purificação do extrato

De cada amostra moída e homogeneizada foram tomados $20 \mathrm{~g}$ e extraidos com $100 \mathrm{ml}$ de acetona a $80 \%$ em liquidificador por $5 \mathrm{~min}$, sendo a sequir filtrado a vácuo, em funil de Büchner, com papel Whatman n: 1. Do filtraco obtico foi tomada uma alíquota de $50 \mathrm{ml}$ em béquer de $250 \mathrm{ml}$ e adicionados $10 \mathrm{ml}$ de acetato de chumbo a $20 \%$ mais $30 \mathrm{ml}$ de água destilada. Em seguida, a mistura foi agitada gentilmente em movimentos circulares e deixada em repouso por $5 \mathrm{~min}$. Após descanso, foi feita uma segunda filtração diretamente para um funil de separação de $250 \mathrm{ml}$, lavando-se o filtro com $10 \mathrm{ml}$ de acetona a $20 \%$ e depois com $10 \mathrm{ml}$ de água destilada.

Para extrair as aflatoxinas do filtrado foram utilizadas 2 porções de $25 \mathrm{ml}$ de clorofórmio. Após agitação ocorreu a separação das fases e a camada de clorofórmio (inferior) foi passaảa para um béquer de $250 \mathrm{ml}$, onde foram adicionados aproximadamente $10 . \mathrm{g}$ de sulfato de sōdio anidro para retirada de água. A seguir, o extrato foi transferido para um balão de destilação de $125 \mathrm{ml}$, lavando-se o sulfato de södio anidro por 3 vezes com $5 \mathrm{ml}$ de clorofórmio.

O extrato contido no balão de destilação foi concentrado em evaporador a vācuo, tipo Rotavapor, até o volume de, aproximadamente, $2 \mathrm{ml}$. Após a concentração do extrato, transferiu-se o mesmo para balão volumëtrico de $5 \mathrm{ml}$, lavando-se o balão de destilação com clorofórmio até completar o volume de $5 \mathrm{ml}$. 


\subsubsection{Cromatografia en camaca delgada}

\section{a) Preparo das placas}

Placas de vidro de $10 \times 20 \mathrm{~cm}$ foram preparadas com camada cie $500 \mu \mathrm{m}$ de silicagel-G, segundo o método de COOMES \& FEUELL (1965) e guardadas en dessecador contendo silicagel indicadora até o momento de serem usadas.

b) Aplicação das amostras e padrão nas placas

A $2 \mathrm{~cm}$ da base das placas foram aplicadas, com auxilio de micropipetas (Drummond Microcaps), alíquotas de $40,30,20,10$ e $5 \mu 1$ do extrato de cada amostra e $5 \mu 1$ de padrão qualitativo das aflatoxinas $B_{1}, B_{2}, G_{1}$ e $G_{2}$ para comparação. A seguir, as placas foram colocadas em cubás de vidro fechadas contendo os solventes tolueno, acetato de etila, ácido fórmico $(5: 4: 1, v / v / v)$. Após o sistema de solventes atingir a altura de $10 \mathrm{~cm}$ acima do local cas alíquotas, as placas foram retiradas e secas com secador.

\section{d) Quantificação das amostras}

Cada placa desenvolvida e seca foi examinada em sala escura, sob lâmpada ultravioleta Philips tipo HPW, de $125 \mathrm{~W}$, com emissão máxima de $365 \mathrm{~nm}$, a uma distância ảe $30 \mathrm{~cm}$. Nestas condições, foi observada a presença ou a ausência de manchas fluorescentes azul-violeta das aflatoxinas $B_{1}$ e $B_{2}$, e esverdeadas das aflatoxinas $G_{1}$ e $G_{2}$ em $R_{f} \doteq 0,45$, $0,40,0,35$ e 0,30 , respectivamente. A quantificação das amostras foi feita visualmente através da técnica de diluição para extinção em que se determinou a menor alíquota onde 
a fluorescência das aflatoxinas foi apenas observada no limite de sua visibilidacie na placa. Nas condições estabelecidas pelo método, o menor valor observado das aflatoxinas $B_{1}$ ' $B_{2}, G_{1} e G_{2}$, no limite de visibilidade, é de $0,40,0,10$, 0,30 e $0,17 \mathrm{ng}$, respectivamente (COOMES \& FEUELL, 1965).

e) Cálculo da concentração das aflatoxinas

As concentrações das aflatoxinas $B_{1}, B_{2}, G_{1}$ e $G_{2}$, presentes na amostra em ppb $(\mu \mathrm{g} / \mathrm{kg})$ foram calculadas pe-lo uso das seguintes förmulas:

$$
\begin{aligned}
& B_{1}(p p b)=\frac{400 \times D}{p \times V} \\
& B_{2}(p p b)=\frac{100 \times D}{p \times V} \\
& G_{1}(p p b)=\frac{300 \times D}{p \times V} \\
& G_{2}(p p b)=\frac{170 \times D}{P \times V}
\end{aligned}
$$

onde: $D=$ volume total, em $m l$, necessärio para diluir ou concentrar o extrato de modo que a fluorescência seja apenas visivel no volume $V$;

$\mathrm{V}=$ volume, em $\mu l$, da menor alíquota onde a fluorescência das aflatoxinas foi observada;

$P=$ peso, em g, da amostra. 
Para interpretação dos resultados das análises foi utilizada a estatística näo-paramêtrica, classificando-se a ocorrência de aflatoxina $B_{1}$, em $p p b$, considerando: ND como zero, < 10 como empate e > 10 o valor direto.

Determinou-se a estatistica $\left(\mathrm{H}_{1}\right)$ do teste de Kruskal-Wallis para grandes amostras e onde ocorreu empates entre observações (CAMPOS, 1983), como se segue:

$$
\mathrm{H}_{1}=\frac{\frac{12}{N(N+I)} \quad \sum_{i=1}^{k} \frac{\mathrm{P}_{i}^{2}}{\mathrm{n}_{i}}-3(\mathrm{~N}+1)}{1-\frac{\sum \mathrm{T}_{i}}{\mathrm{~N}^{3}-\mathrm{N}}}
$$

onde: $\mathrm{N}$ = número total de amostras;

$\mathrm{R}_{\mathrm{i}}=$ soma das ordens atribuídas à i-ésima indústria;

$\mathrm{n}_{i}=$ nümero de amostras da i-ésima indūstria;

$T_{i}=t_{i}^{3}-t_{i}$ para $t_{i}=$ número de amostras empatadas no i-ésimo grupo.

Para aplicação desse teste procedeu-se à classificação conjunta das $\mathrm{N}=\sum_{i-1}^{\mathrm{k}} \mathrm{n}_{i}$ amostras, dando ordem 1 à menor delas e $\mathrm{N}$ à maior. Como ocorreram empates entre as observações, procedeu-se ao desempate, considerando para cada observação no grupo empatado a média das ordens que seriam atribuídas a elas se não houvesse o empate.

Os tratamentos (indústrias) foram confrontados 2 a 2 pelo mētodo das comparaçōes mültiplas a uma taxa de erro experimental $\alpha=0,05$, para 0 caso de grandes amostras e de tratamentos não igualmente repeticos, segundo 
CAMPOS (1983):

$$
\text { d.m.s. }=z_{\alpha /}[k(k-1)] \sqrt{\frac{N(N+1)}{12}} \frac{\left(-\frac{1}{n_{i}}+\frac{1}{n_{j}}\right)}{}
$$

onde: $\mathrm{Z}_{\alpha /}[\mathrm{k}(\mathrm{k}-1)]$ = limite superior da distribuição normal;

$\mathrm{N}=$ número total de amostras;

$\mathrm{n}_{i}, \mathrm{n}_{j}=$ número de amostras da i-ésima $e$. j-ésima indústria, respectivamente. 


\section{RESULTADOS E DISCUSSÃO}

Os resultados das análises de aflatoxina $B_{1}$ são apresentados nas tabelas 2 a 7 e os resultados das análises estatisticas encontram-se nas tabelas 8 e 9 .

Conforme pode-se verificar nas tabelas de 2 a 7 a $B_{1}$ foi a única aflatoxina encontrada e o número de amostras contaminadas atingiu a 114, representando $67,45 \%$ do total. Observa-se também, nestas tabelas, que os níveis da referida toxina encontrados nas amostras contaminadas variaram de menos de 10 a 40 ppb. Estes mesmos resultados mostram que houve variação na ocorrência e no nivel de contaminação do material estudado entre as fābricas ou regiões.

Os procedimentos não-paramétricos de KruskalWallis e de Comparações Múltiplas foram aplicados para verificar a existência àe diferença significativa entre a ocorrência e os teores de aflatoxina $B_{1}$ conforme as regiões. Foi encontrado o valor $\mathrm{H}_{1}=52,03$, evidenciando-se nas tabelas 8 e 9 que as regiões diferem entre sí quanto ao teor de aflatoxina $B_{1}$ ao nivel de 0,01 àe probabilidade.

Confrontando-se as tabelas 2,3 e 9 constatase que a menor ocorréncia e os mais baixos teores de aflatoxina $\mathrm{B}_{1}$ foram encontrados em Araraquara, diferindo significativamente $(\alpha=0,05)$ de outras regiões como Paraguaçu Paulista, Londrina e Maringá. Por outro lado, observa-se que Maringá foi a região que apresentou a maior ocorrência e os 
teores mais elevados de aflatoxina $B_{1}$, diferindo significativamente $(\alpha=0,05)$ de Bauru, Campinas e Guararanes (Tabelas 4, 5, 6 e 9). Observa-se ainca, nas tabelas 2, 5, 6 e 9 que na região de Londrina a ocorrência e os teores de aflatoxina $B_{1}$ foram significativamente $(\alpha=0,05)$ maiores do que nas regiões de Campinas e Guararapes.

Pode-se também constatar, nas tabelas 4 e 9 , que entre as regiões de Bauru e Maringã não houve diferença significativa quanto ao teor de aflatoxina $B_{1}$. Este mesmo resultado foi tambēm verificado entre as indūstrias localizadas em Maringá (Tabelas 3 e 4 ).

Analisando-se os resultados da tabela 7 verifica-se que não houve predominância da ocorrência de aflatoxina $B_{1}$ em qualquer época durante toda a safra.

TABELA 2 - Ocorrência de aflatoxina $B_{1}$ (ppb) em: farelo de algodão, em diversas épocas, proveniente da empresa "A", Araraquara (SP), Paraguaçu Paulista (SP) e Londrina ( $P R$ ), no ano de 1986 (média semanal).

Epocas de coleta

EMPRESA "A"

Araraquara Paraguaçu Paulista Lonàrina

28.04 a 04.05

05.05 a 11.05

ND

10

12.05 a 18.05

ND

10

13

40

19.05 a 25.05

13

40

26.05 a 01.06

ND

20

02.06 a 08.06

13

10

09.06 a 15.06

$<10$

10

16.06 a 22.06

$<10$

20

10

23.06 a 29.06

$<10$

16

10

30.06 a 06.07

ND

20

27 
TABELA 2 - Ocorréncia de aflatoxina $B_{1}$ (ppb) em farelo de algodão, em àiversas épocas, proveniente da empresa "A", Araraquara (SP), Paraguaçu Paulista (SP) e Londrina (PR), no ano de 1986 (méciia semanal).

Epocas cie coleta

EMPRESA " $\mathrm{A} "$

Araraquara Paraçuaçu faulista Londrina

07.07 a 13.07

20

27

27

14.07 a 20.07

$\mathrm{ND}$

40

27

21.07 a 26.07

ND

$<10$

10

27.07 a 03.08

ND

ND

10

04.08 a 10.08

ND

ND

ND

$11.08 \mathrm{a} 17.08$

$<10$

$<10$

40

18.08 a 24.08

ND

$<10$

20

25.08 a 31.08

ND

13

20

01.09 a 06.09

ND

$<10$

13

07.09 a 13.09

ND

10

ND

14.09 a 20.09

$<10$

10

10

22.09 a 28.09

$<10$

$<10$

20

29.09 a 05.10

ND

$<10$

10

06.10 a 11.10

ND

10

10

12.10 a 18.10

ND

$<10$

20

19.10 a 23.10

ND

24.10 a 01.11

ND

02.11 a 09.11

10

10.11 a 16.11

10

17.11 a 24.11

ND

25.11 a 01.12

$<10$

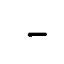

$-$

Total de amostras contaminadas

13

23

16

$\mathrm{ND}=$ Não detectada

$(-)=$ Amostras não enviadas pelas indústrias. 
TABELA 3 - Ocorrência de aflatoxina $B_{1}$ (ppb) em farelo de algodão, em diversas épocas, proveniente da empresa " $\mathrm{B}$ ", Maringá (PR), no ano de 1986 (média semana.l).

\begin{tabular}{lc}
\hline Epocas de coleta & ERPRESA "B" \\
\hline 07.04 a 13.04 & 40 \\
14.04 a 18.04 & 40 \\
21.04 a 27.04 & 40 \\
28.04 a 04.05 & 20 \\
05.05 a 09.05 & 20 \\
12.05 a 18.05 & 20 \\
19.05 a 24.05 & 20 \\
27.05 a 31.05 & 40 \\
02.06 a 07.06 & 20 \\
09.06 a 14.06 & 10 \\
17.06 a 22.06 & 10 \\
23.06 a 28.06 & 20 \\
29.06 a 02.07 & 40 \\
\hline Total de amostras contaminadas & 13 \\
\hline
\end{tabular}


TABELA 4 - Ocorrência de aflatoxina $B_{1}$ (ppb) em farelo de algodão, em diversas épocas, proveniente da empresa "C", Bauru (SP) e Maringá (PR), no ano de 1986 (média semanal).

\begin{tabular}{|c|c|c|}
\hline \multirow{2}{*}{ Epocas de coleta } & \multicolumn{2}{|c|}{ EMPRESA "C" } \\
\hline & Bauru & Maringá \\
\hline 15.04 a 19.04 & - & 40 \\
\hline 20.04 a 26.04 & 40 & 40 \\
\hline 27.04 a 05.05 & 20 & 27 \\
\hline 06.05 a 12.05 & - & 20 \\
\hline 13.05 a 18.05 & 20 & 40 \\
\hline 19.05 a 26.05 & 10 & 20 \\
\hline 27.05 a 01.06 & 10 & $<10$ \\
\hline 02.06 a 08.06 & 10 & $<10$ \\
\hline 09.06 a 15.06 & $<10$ & $<10$ \\
\hline 16.06 a 22.06 & ND & 10 \\
\hline 23.06 a 29.06 & 11 & 27 \\
\hline 30.06 a 06.07 & 16 & 20 \\
\hline 07.07 a 13.07 & 20 & 27 \\
\hline 14.07 a 20.07 & 13 & 10 \\
\hline 21.07 a 27.07 & $<10$ & ND \\
\hline 28.07 a 04.08 & ND & ND \\
\hline 05.08 a 11.08 & $N D$ & 40 \\
\hline $12.08 \mathrm{a} 17.08$ & 13 & $<10$ \\
\hline 18.08 a 24.08 & ND & ND \\
\hline 25.08 a 01.09 & ND & $<10$ \\
\hline
\end{tabular}


TABELA 4 - Ocorrência de aflatoxina $B_{1}$ (ppb) em farelo de algodão, em diversas épocas, proveniente da empresa "C", Bauru (SP) e Maringá (PR), no ano de 1986 (média semanal).

\begin{tabular}{lcc}
\hline Epocas de coleta & \multicolumn{2}{c}{ EMPRESA "C" } \\
\cline { 2 - 3 } 02.09 a 07.09 & ND & Maringá \\
08.09 a 14.09 & ND & ND \\
15.09 a 21.09 & ND & ND \\
22.09 a 28.09 & ND & 10 \\
29.09 a 05.10 & ND & 10 \\
06.10 a 12.10 & ND & - \\
12.10 a 19.10 & ND & - \\
\hline Total de amostras contaminatas & 13 & - \\
\hline
\end{tabular}

ND = Não detectaảa

$(-)=$ Amostras não enviadas pelas indústrias. 
TABELA 5 - Ocorrência de aflatoxina $B_{1}$ (ppb) em farelo de algodão, em diversas épocas, proveniente da empresa "D", Camninas (SP), no ano de 1986 (média semanal).

Epocas de coleta

EMPRESA "D"

\section{Campinas}

21.04 a 27.04

13

28.04 a 07.05

ND

08.05 a 19.05

20

20.05 a 04.06

ND

05.06 a 24.06

ND

25.06 a 24.07

$<10$

25.07 a 25.08

ND

26.08 a 21.09

ND

22.09 a 30.09

ND

01.10 a 14.10

10

Total de amostras contaminadas

$\mathrm{ND}=\mathrm{Não}$ detectada 
TABELA 6 - Ocorrência cie aflatoxina $B_{1}$ (ppo) em farelo de algodão, em diversas épocas, proveniente da empresa "E", Guararapes (SP), no ano de 1986 (mëdia semanal).

\begin{tabular}{llc}
\hline Epocas de coleta & EMPRESA "E" \\
\hline 12.05 a 18.05 & 10 \\
19.05 a 25.05 & 10 \\
26.05 a 01.06 & 10 \\
02.06 a 08.06 & 10 \\
09.06 a 15.06 & ND \\
16.06 a 22.06 & $<10$ \\
23.06 a 29.06 & 10 \\
30.06 a 06.07 & ND \\
07.07 a 13.07 & 13 \\
14.07 a 20.07 & ND \\
21.07 a 27.07 & ND \\
11.08 a 17.08 & $<10$ \\
18.08 a 24.08 & ND \\
25.08 a 31.08 & $<10$ \\
01.09 a 07.09 & ND \\
08.09 a 14.09 & ND \\
15.09 a 21.09 & ND \\
22.09 a 29.09 & ND \\
30.09 a 05.10 & ND \\
06.10 a 12.10 & 10 \\
13.10 a 19.10 & 10 \\
20.10 a 26.10 & $<10$ \\
27.10 a 01.11 & $<10$ \\
\hline Total de amostras contaminadas & 13 \\
\hline
\end{tabular}

ND $=$ Não detectada 


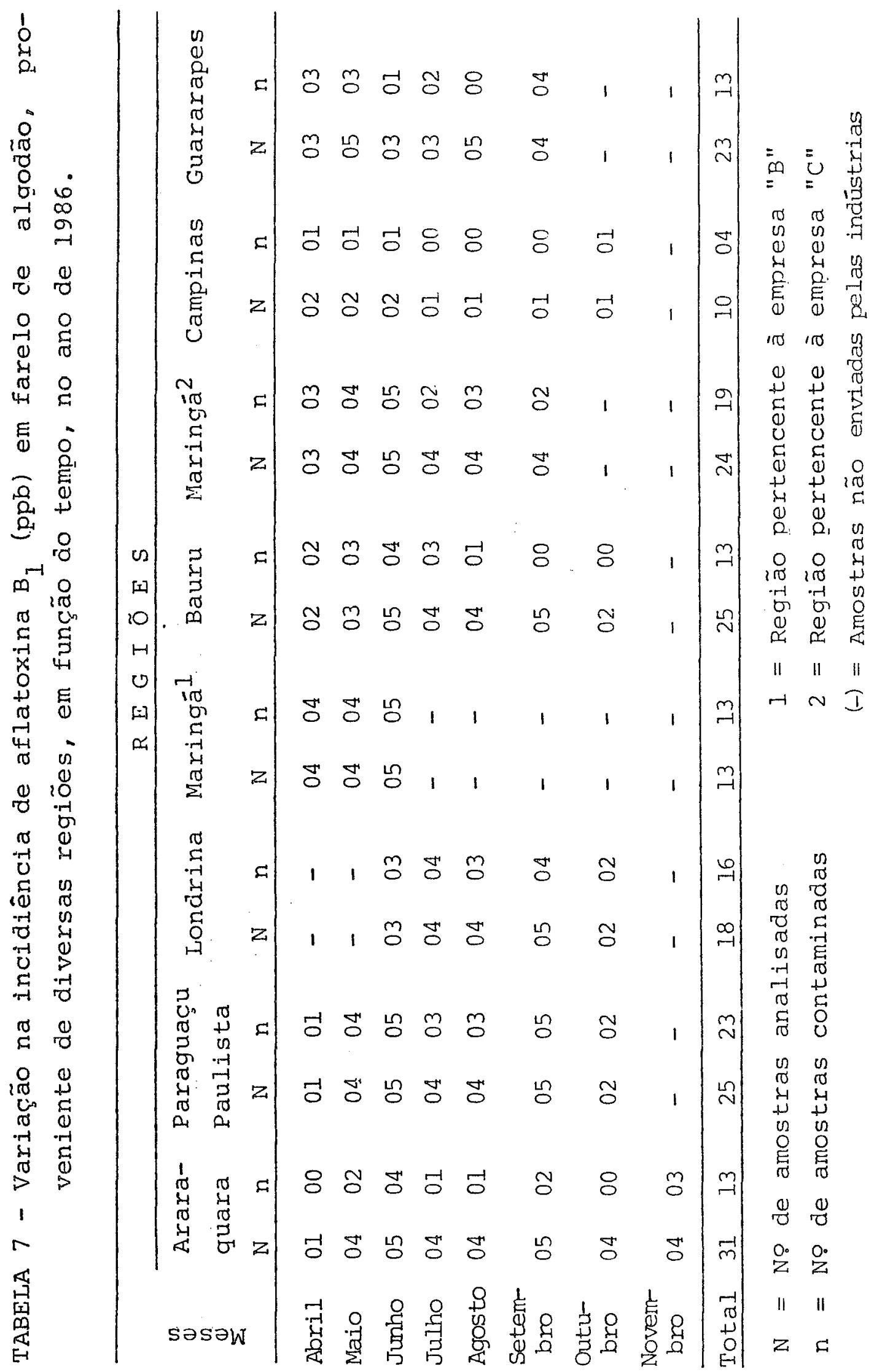




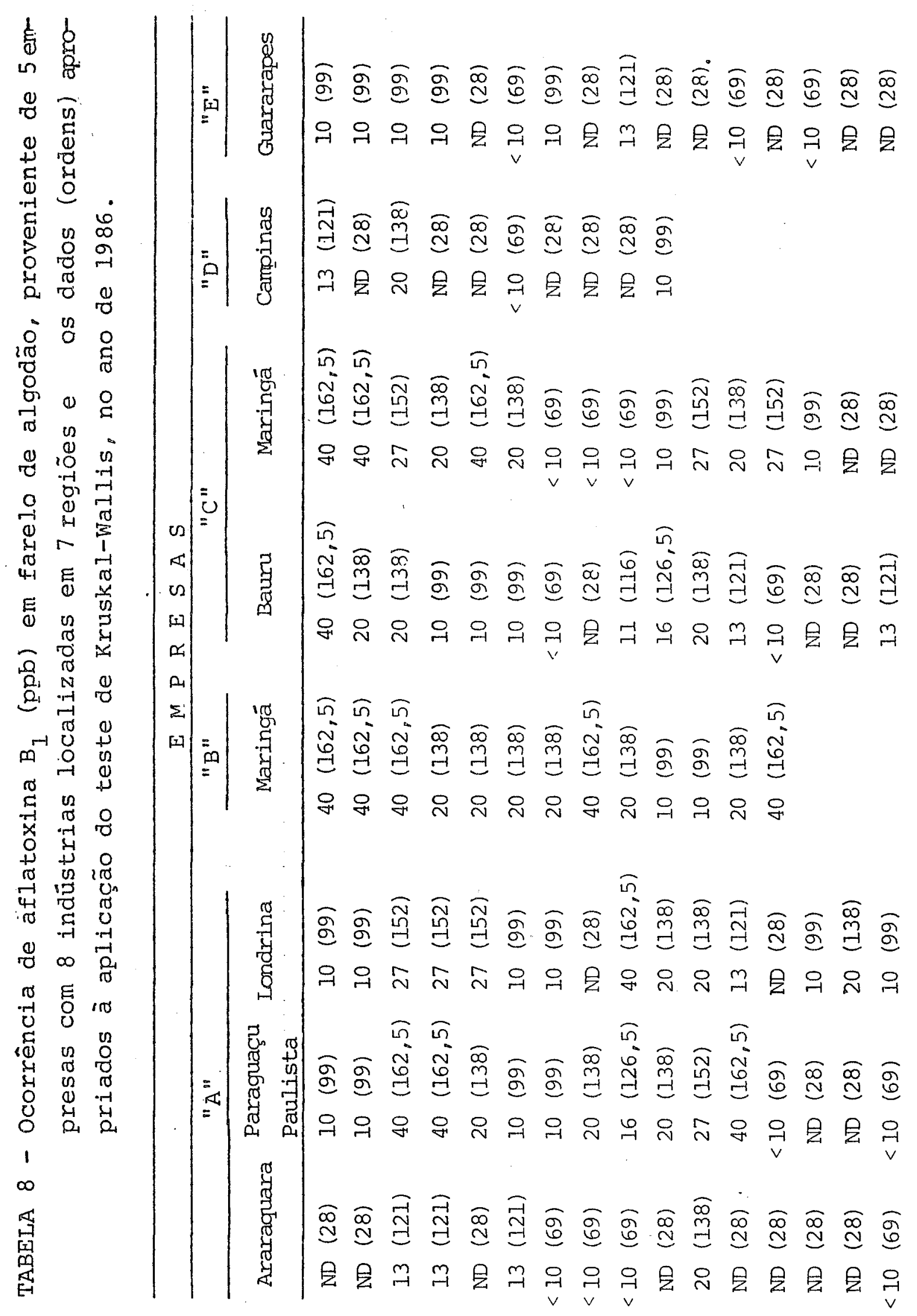




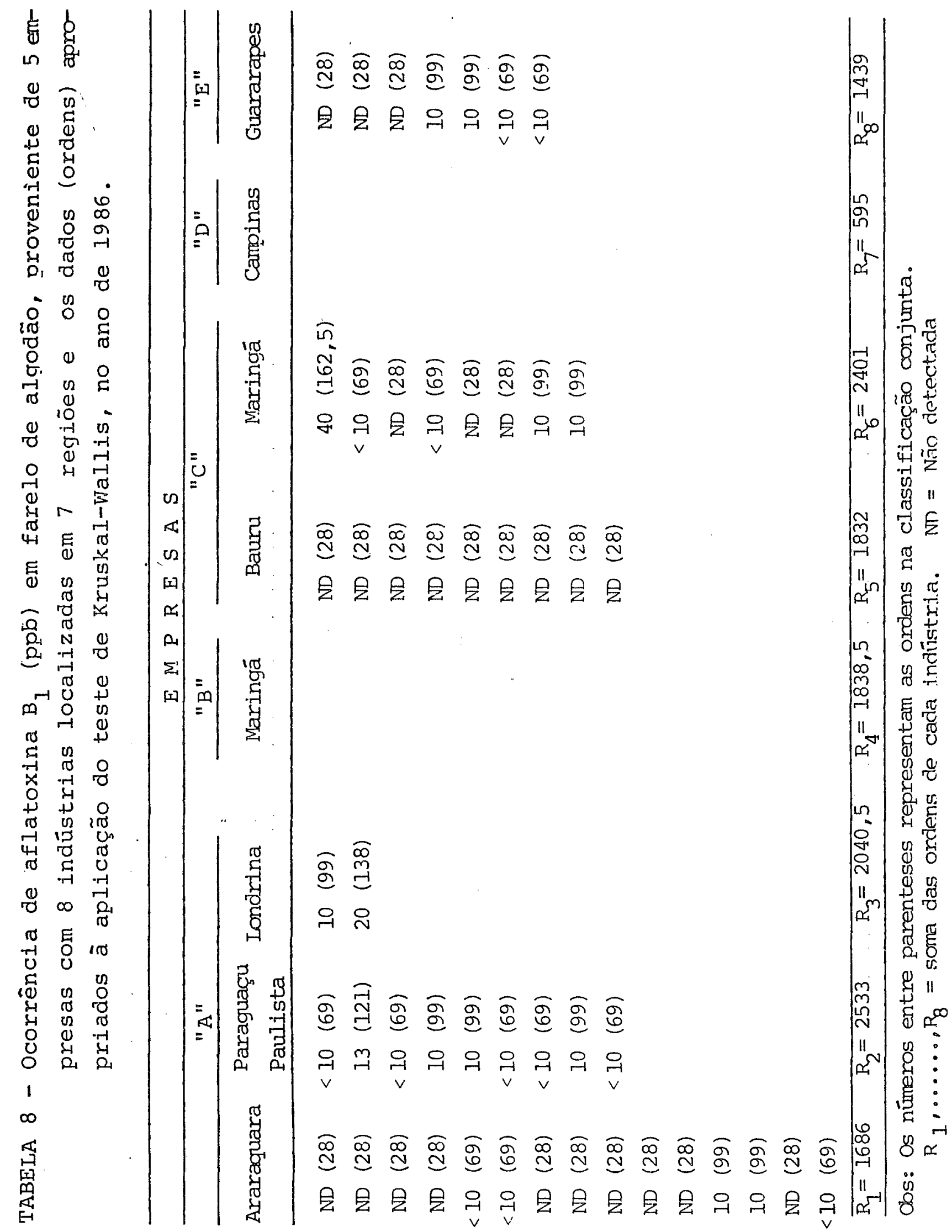


TABELA 9 - Diferenças $\left|\bar{R}_{i}-\bar{R}_{j}\right|$ em valores absolutos entre pares de médias das somas das ordens atribuidas às indústrias na classificação conjunta das 169 amostras de ocorrência de aflatoxina $B_{1}$ (ppb) em farelo de algodão, no ano de 1986.

\begin{tabular}{|c|c|c|}
\hline Indūstrias & $\left|\bar{R}_{i}-\bar{P}_{j}\right|$ & d.m.s. ${ }^{(*)}$ \\
\hline (Araraquara, Paraguaçu Paulista) & 46,93 & 41,17 \\
\hline (Araraquara, Londrina) & 58,97 & 45,38 \\
\hline (Araraquara, Maringāi) & 87,03 & 50,60 \\
\hline (Araraquara, Bauru) & 18,89 & 41,64 \\
\hline (Araraquara, Maringa $\vec{a}^{2}$ ) & 45,65 & 41,64 \\
\hline (Araraquara, Campinas) & 5,11 & 55,70 \\
\hline (Araraquara, Guararapes) & 8,17 & 42,15 \\
\hline (Paraguaçu Paulista, Londrina) & 12,04 & 47,34 \\
\hline (Paraguaçu Paulista, Maringá-1) & 40,10 & 52,37 \\
\hline (Paraguaçu Paulista, Bauru) & 28,04 & 43,32 \\
\hline (Paraguaçu Paulista, Maringa $\bar{a}^{-2}$ ) & 1,28 & 43,77 \\
\hline (Paraguaçu Paulista, Campinas) & 41,82 & 57,30 \\
\hline (Paraguaçu Paulista, Guararapes) & 38,76 & 44,25 \\
\hline (Londrina, Maringāi ) & 28,06 & 55,74 \\
\hline (Londrina, Bauru) & 40,08 & 47,34 \\
\hline (Londrina, Maringā2) & 13,32 & 47,75 \\
\hline (Londrina, Campinas) & 53,86 & 50,40 \\
\hline (Londrina, Guararapes) & 50,80 & 48,20 \\
\hline (Maringä ${ }^{1}$, Bauru) & 68,14 & 52,37 \\
\hline (Maringa ${ }^{-1}$, Maringa ${ }^{2}$ ) & 41,38 & 52,74 \\
\hline
\end{tabular}


TABELA 9 - Diferenças $\left|\bar{R}_{j}-\bar{R}_{j}\right|$ em valores absolutos entre pares de médias das somas das ordens atribuidas às indústrias na classificação conjunta das 169 amostras de ocorrência de aflatoxina $B_{1}$ (ppb), em farelo de algoãão, no ano de 1986 .

\begin{tabular}{|c|c|c|}
\hline Inảūstrias. & $\left|\bar{R}_{i}-\bar{R}_{j}\right|$ & $\mathrm{d} \cdot \mathrm{m} \cdot \mathrm{s} \cdot{ }^{(*)}$ \\
\hline (Maringā1, Campinas) & 81,92 & 64,42 \\
\hline (Maringā , Guararapes) & 78,86 & 53,14 \\
\hline (Bauru, Maringä2) & 26,76 & 43,77 \\
\hline (Bauru, Campinas) & 13,78 & 57,30 \\
\hline (Bauru, Guararapes) & 10,72 & $.44,25$ \\
\hline (Maringä ${ }^{2}$, Campinas) & 40,54 & 57,64 \\
\hline (Maringán ${ }^{2}$, Guararapes) & 37,48 & 44,69 \\
\hline (Campinas, Guararapes) & 3,06 & 58,01 \\
\hline
\end{tabular}

${ }^{(*)}$ d.m.s. = Diferença minima significativa a uma "taxa de erro experimental" $\alpha=0,05$, pelo teste de Comparações Múltiplas.

$1=$ Região pertencente à empresa "B".

2 = Região pertencente à empresa "C".

Dentre os fatores que podem ter contribuido para a diferença de contaminação do farelo de algodão entre as regiōes, o climātico deve ter sido o preponderante. o teor de umidade da matéria-prima ao chegar nas fábricas, provavelmente deve ter sido diferente de uma região para outra. A temperatura e o teor de umidade relativa do ar, as condições e o tempo de armazenamento, tamiém devem ter influenciado na incidência de contaminação assim como o ataque de 
insetos tanto no campo como no armazém, como resultado da diferença de controle de pragas pelos agricultores.

Segundo ABRAHÃO, se a colheita do algodão for realizada em época de muita chuva a possibilidade de contaminação é muito grande. O pico máximo de colheita do algodão ocorre entre os meses de março e abril, época em que a temperatura e as chuvas tendem a diminuir, porém, isso é muito variável de um ano para outro e de uma região para outra, podendo ocorrer chuvas ocasionais.

Os mais altos níveis de contaminação do àlgodão com aflatoxina ocorrem no sudeste dos Estados Unidos, onde as condições climāticas, como temperatura e umidade, sãc. favoráveis ao fungo para produção de aflatoxinas (MARSH et alii, 1973; WESSELL \& STOLOFF, 1973; VELASCO et alii, 1975; RUSSELL et alii, 1976; HAMSA \& AYRE'S, 1977; RUSSELL \& LEE, 1985; LEE et alii, 1986; MYCOTOXINS and food safety, 1986). Naquela região, ocorre altas temperaturas e, por causa da aplica ção de práticas de irrigação, a umidade do ar é elevada. Estas características são muito semelhantes e algumas das condições observadas no Brasil em determinadas épocas do ano.

Entretanto, mesmo sabendo-se que todos esses fatores possam ter influenciado as variações que ocorreram no teor de aflatoxina $B_{1}$ entre as regiões, é difícil indicar com precisão qual a causa específica da maior incidência da aflatoxina em Maringā. Mesmo assim, acredita-se que o teor de umidade da matéria-prima recebida pela fábrica localizada na região de Maringá deve ter sido elevado, podendo este fator ser indicado como o principal responsável pela diferença encontrada na ocorrência da aflatoxina entre as regiões.

\footnotetext{
*ABRAHÃO, J.T.M. (Escola Superior de Agricultura "Luiz de Queiroz" ESALQ/USP) Comunicação pessoal, 1987.
} 
Sabe-se, com base nos trabalhos de ASilwORTH JUNIOR \& MCMEANS (1966), WIDSTROM (1979) e KLICH \& LEE (1982), que o campo é o principal local de contaminação da cultura algodoeira. Alēm disso, o teor de umidade da semente de algodão em equilíbrio com a umidade relativa do ambiente é, também, uma variável bastante efetiva no controle da infecção.

WHITTEN \& SMITH (1972), estudando o conteúdo de umidade de sementes estocadas, verificaram que a variação de $15,1 \%$ para $21,8 \%$ é suficiente para aumentar em 10 vezes 0 teor de aflatoxina.

Segundo FONSECA (s.d.) o nível de umidade ideal para que o farelo possa ser armazenado com seguran ça, está em torno de 10\%. Com este valor de umidade, o desenvolvimento de fungos e a produção de toxinas, com certeza será limitado.

De acordo com estudos realizados, tortas ou farelos contendo teores de até 100 ppo de aflatoxina podem ser utilizados, em proporções que variam de 5 a 15\%, nas ra ções destinadas a determinadas espécies de animais (FAO, 1979). Dentro desta categoria, considerada como ligeiramente positiva," estão enquadradas as amostras de farelo de algodão do presente trabalho contaminadas com aflatoxina $B_{1}$. Assim, pode-se dizer que, embora a toxina $B_{1}$, tenha sido encontrada na maioria dos farelos analisados $(67,45 \%)$, estes podem ser usados em proporções normais na composição de rações, porque o nível de contaminação do material foi baixo nesta safra.

Segundo as normas brasileiras (FONSECA, 1983), - limite de $30 \mathrm{ppb}$ é o máximo permitido para as aflatoxinas $\mathrm{B}_{1}+\mathrm{G}_{1}$, em alimentos para consumo humana. Isto significa que, dentro desta categoria, as amostras com 40 ppo de 
aflatoxina $B_{1}$, O que representa $12,30 \%$ do total contaminado, não devem ser utilizadas. O restante, 87,70 용 contém teores de aflatoxina $B_{1}$ variando de menos de 10 a $27 \mathrm{ppb}$ e pode ser aproveitado com esta finalidade.

A determinação da ocorrēncia de aflatoxinas em trabalhos semelhantes já foi efetuada por LOOSMORE et alii (1964), que constataram a presença de aflatoxina $B_{1}$ em elevados níveis de toxidez.

Os resultados da análise do tipo de aflatoxina presente em farelo de algodão revelaram, como já foi dito anteriormente, que a $B_{1}$ foi a única do grupo encontrada em todas as amostras. Estes resultados diferem dos obtidos por MAYNE et alii (1966). Os autores, ao estudarem a ocorrência de aflatoxinas em sementes e farelo de algodão encontraram com maior frequência as aflatoxinas $B_{1}$ e $B_{2}$.

Em trabalho mais recente PONS JUNIOR et alii (1980), encontraram também os metabólitos $B_{1}$ e $B_{2}$ em farelo de algodão. Em contrapartida, ENGEBRECHT et alii (1965), em suas pesquisas, constataram apenas a $B_{1}$ em 4 das 8 amostras examinadas, em quantidades variando de 19 a 186 ppb.

SCHNEIDER et alii (1972), trabalhando em pesquisas semelhantes na Guatemala, na Nicaragua e em El Salvador, demonstraram que em todas as regiões pesquisadas a afla toxina $B_{1}$ foi a única encontrada em todas as amostras contaminadas.

Sabe-se, porém, segundo os trabalhos de MAYNE et alii (1966), GOLDBIATT (1971) e ORGANIZACION PANAMERICANA DE LA SALUD (1983), que as aflatoxinas $B_{1}, B_{2}, G_{1}$ e $G_{2}$ podem ocorrer concomitantemente ou não. O tipo e o teor de toxina no alimento ou na ração podem ser influenciados por̀ vários fatores, como o ambiente, o substrato e a linnagem do fungo. Em adição a estas causas, o trabalno realizado por 
MAYNE (1966), também considera o gossipol como um agente que pode modificar a produção de aflatoxinas pelo Aspergillus fla vus.

Pelos relatos de HARTLEY et alii (1963) e CUCULLU et alii (1966), as aflatoxinas $B_{1}$ e $B_{2}$ são normalmente produzidas na proporção de $40: 1$. Com base neste dado, pode-se também justificar que a presença de apenas uma toxina, nos farelos analisados, seja devido ao baixo indice de contaminação do material. 


\section{CONCIOSQTES}

Face aos resultados obtidos, concluiu-se que:

1) das 169 amostras de farelo de algodão da safra de 1986, 67,45\% estavam contaminadas;

2) O nível de contaminação foi pequeno, pois - teor máximo encontrado foi de $40 \mathrm{ppb} e$ as amostras que apresentaram este valor representaram apenas $12,30 \%$ de todo o material contaminacio;

3) há eviâências, pela análise estatística de que houve diferença entre as regiões estudadas, tendo Araraquara (SP), Campinas (SP) e Bauru (SP) apresentado a menor ocorrência e os teores mais baixos de aflatoxina $\mathrm{B}_{1}$, enquanto Maringá (PR) apresentou a maior ocorrência e os mais elevados teores de aflatoxina $B_{1}$;

4) não houve predominância da incicência de aflatoxina $B_{1}$ em qualquer época durante toda a safra;

5) a ünica aflatoxina encontrada foi a $B_{1}$. 


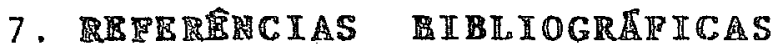

ABRAHÃO, J. T. M.; D'ARCE, M. A. B. R.; FONSECA, H. Algodãoprodução, pré-processamento e transformação agroindustrial. São Paulo, Secretaria da Indústria, Comércio, Ciência e Tecnologia, s.d. 96 p. (Série extensão agroindustrial, 2)

ALBERT, M. E. \& DAVIDSON, C. S. Mycotoxins: a possible cause. of primary carcinoma of the liver. The American Journal of Clinical Nutrition, Bethesda, 46 (3):325-9, 1969.

ALLCROFT, R. \& LEWIS, G. Groundnut toxicity in cattle: experimental poisoning of calves and a report on clinical effects in older cattle. The Veterinary Record, London, 75 (19): 487-94, 1963.

'ALLCROFT, R.; ROGERS, H.; LEWIS, G.; NABNEY, J.; BEST, P. E. Metabolism of aflatoxin in sheep: excretion of the "milk toxin". Nature, London, 209 (5019): 154-5, 1966.

ASHWORTH JUNIOR, L. J. \& MCMEANS, J. L. Association of Aspergillus flavus and aflatoxins with a greenish yellow fluorescence of cotton seed. Phytopathology, St. Paul, 56 (9): $1104-5,1966$. 
ASHWORTH JUNIOR, L. J.; MCMEANS, J. L。: BROWN, C. M. Infection of cotton by Aspergillus flavus: the influence of temperature ana aeration. Phytopathology, St. Paul, 59 (5): 669-73, $1969 \mathrm{a}$.

ASHWORTH JUNIOR, L. J.; MCMEANS, J. L.; BROWN, C. M. Infection of cotton by Aspergillus flavus: time of infection and the influence of fiber moisture. Phytopathology, St. Paul, 59 (5): $383-5,1969 b$.

ASHWORTH JUNIOR, L. J。; MCMEANS, J.L.; HOUSTON, B. R.; KHITTEN, M. E.; BROWN, C. M. Mycoflora, aflatoxins and free fatty acids in California cottonseed during 1967-1968. Journal of the American Oil Chemists' Society, Chicago, 48 (3): 129-33, 1971a.

ASHWORTH JUNIOR, L. J.; MCMEANS, J.L.; PYLE, J. L.; BROWN, C. M.; OSGOOD, J. W.; PONTON, R.E. Aflatoxins in cotton seeds: influence of weathering on toxin content of seed and on a method for mechanically sorting seed lots. Phytopathology, St. Paul, 58 (1): 102-7, 1968 .

ASHWORTH JUNIOR, L. J.; RICE, R. E.; MCMEANS, J.I.; BROWN, C. M. The relationship of insects to infection of cotton bolls by Aspergillus flavus. Phytopathology, St. Paul, 6I: $488-93,1971 \mathrm{~b}$.

ASPLIN, F. D. \& CARNAGHAN, R. B. A. The toxicity of certain groundnut meals for poultry with special reference to their effect on ducklings and chickens. The Veterinary Record, London, 73 (46): 1215-9, 1961.

BANKS JUNIOR, W. L。; ALIISON, J. B.; WANNEMACHER JUNIOR, R。 W. Supplementation of wheat gluten protein. Journal of Nutrition, Bethesda, 82: 61-6, 1964. 
BLOUNT, W. P. "Disease" of turkey poults. The Veterinary Record, London, 72 (38): 786,1960 .

BOLLENBACHER, K. \& MARSH, P.B. A preliminary note on a Eluorescent fiber condition in raw cotton. The Plant Disease Reporter, Washington, 38 (6): 375-9, 1954 .

BRAZZEL, J. R. The pink bollworm as a factor in cotton boll rots. The Plant Disease Reporter, Washington, 39 (7): $583-4,1955$.

BRESSANI, R.; ABURTO, A.; GOMEZ-BRENES, R.; BRAHAM, E. Efecto del gosipol libre de diferentes harinas aje algodón sobre el crecimiento de ratas y niveles de lisina libre y gosipol libre en órganos, músculo y suero de animales. Archivos Latinoamericanos de Nutricion, Caracas, 25 (1): 47-66, 1975 .

BUCKLE, T. S. de. \& SILVA, G. S. Aisalado de proteínas a partir de tortas de algodão colombianas. Revista del Instituto de Investigaciones Tecnológicas, Bogotá, 95: 1731. 1975 .

CAMARGo, C. R". de. O. Efeito da interação das condições de extrusão e da amônia e/ou metilamina na degradação de aflatoxina em farinhas de arroz. Campinas, 1986. 133 p. [Doutoramento - UNICAMP].

CAMPBELL, T. C. \& STOLOFF, L. Implication of mycotoxins for human health. Journal of Agricultural and Food Chemistry, Washington, 22 (6): 1006-15, 1974 .

CAMPos, H. Estatistica experimental não-paramëtrica. 4. ed. Piracicaba, Escola Superior de Agricultura "Luiz de Queiroz", 1983. $349 \mathrm{p}$. 
CARNAGHAN, R. B. A. \& SARGEANT, K. The toxicity of certain groundnut meals to poultry. The Veterinary Record, Iondon, 73 (29): $726-7,1961$.

CARVALHO, V. D. de. \& CHALFOUN, S. M. Aflatoxinas em amendoim: como evitar contaminacões. Belo Horizonte, Empresa de Pesquisa Agropecuaria de Minas Gerais, 1984. 4 p. (Pesquisando, 127)

CHRISTENSEN, C. M. Deterioration of stored grain by fungi. Botanical Review, New York, 23: 108-34, 1957.

CLEGG, F. G. \& BRYSON, H. An outbreak of poisoning in store cattle attributed to Brazilian groundnut meal. The Vetexinary Record, London, 74 (37): 992-4, 1962.

CLIFFORD; J. I. \& REES, K. R. The action of aflatoxin $B_{1}$ on the rat liver. The Biochemical Journal, London, 102 (1): $65-75,1965$.

COOMES, T. J. \& FEUELL, A. J. Recommended procedures for the detection and estimation of aflatoxin $B_{-}$in groundnuts and groundnut materials. London, Tropical Products Institute, 1965. 24 p. (TPI Report, G 13)

CostA, S. I. da. Aflatoxina. Boletim do Centro Tropical de Pesquisas e Tecnologia de Alimentos, Campinas, 12: 27-36, 1967.

CUCULLU, A. F。; LEE, L. S.; MAYNE, R. Y.: GOLDBLATT, L. A. Determination of aflatoxins in individual peanuts and peanut sections. Journal of the American Oil Chemists' Society, Chicago, 43 (2): 89-92, 1966. 
CUCULLU, A. E.; PONS JUNIOR, W. A.; GOLDBLATT, L. A. Fast screening method for detection of aflatoxin contamination in cottonseed products. Journal of the Association of Official Analytical Chemistry, Washington, 55 (5): 1114-9, 1972 .

DAVIDSON, C. S. Nutrition, geography, and liver diseases. The American Journal of Clinical Nutrition, Bethesda, 23 (4) : 427-36, 1970 .

DE IONGH, H.; VLES, R. O.; VAN PELT, J. G. Milk of mammals fed on aflatoxin-containing diet. Nature, London, 202 $(4931): 466-7,1964$.

DUTTON, M. F. \& HEATHCOTE, J. G. Two new hydroxy aflatoxins. The Biochemical Journal, Iondon, 101 (2): $21 \mathrm{P}-2 \mathrm{P}, 1966$.

EDDS, G. T. Acute aflatoxicosis: a review. Journal of American Veterinary Medical Association, Schaumburg, 162 (4): $304-9,1973$.

ELIAS, I. G. \& BRESSANI, R. Estudio comparativo de diferentes métodos para evaluacion del valor proteico de harinas de semilla de "algodón. Archivos Latinoamericanos de Nutricion, Caracas, 3 (19): 279-307, 1969 .

ENGEBRECHT, R. H.; AYRES, J. L。; SINNHUBER, R. O. Isolation and determination of aflatoxin $B_{1}$ in cottonseed meals. Journal of the Association of Official Analytical Chemistry, Washington, 48 (4): $815-7,1965$.

FAO-FOOD AND AGRICULTURE ORGANIZATION OF THE UNITED NATIONS. Recommended practices for the prevention of mycotoxins in food, feed and their products. Roma, 1979. 71 p. (Food and nutrition paper, 10) 
FARAG, R. S.; EL-LEITHY, M. A。; BASYONY, A. E.; DAN, Z. Y. Effects of varied substrates on aflatoxin production by A. parasiticus. Journal of the American Oil Chemists' Society, Chicago, 63 (8): 1024-6, 1986.

FONSECA, H. Aflatoxina em amendoim. São Paulo, Secretaria de Agricultura e Abastecimento/Coordenadoria de Assistência' Técnica Integral, 1983. $12 \mathrm{p}$. (Documento técnico, 46)

FONSECA, H. Contribuição ao estudo da aflatoxina no amendoim (Arachis hypogaea I.) da colheita à industrializacão. Piracicaba, 1969. 8] D. [Livre Docēncia - ESALQ].

FONSECA, H. Levantamento do teor de aflatoxina em tortas e farelos de amendoim (Arachis hypogaea L.) no Estado de são Paulo: Piracicaba, 1968. 64 p. [Doutoramento - ESALQ].

FONSECA, H. Ocorrência de aflatoxina em alimentos. In: SEMINARIO LATINO AMERICANO SOBRE TOXICOLOGIA DE ALIMENTOS, Campinas, 1983. Anais. Campinas, Universidade Estadual de Campinas, 1984. p. 170-80.

FONSECA, H. Tecnologia de transformação. In: ABRAHÃO, J.T. M.; D'ARCE, M. A. B. R.; FONSECA, H. Algodão-produção, prë-processamento e transformação agroindustrial. São Paulo, Secretaria da Indūstria, Comërcio, Ciência e Tecnologia, s.d. p. 57-96. (Sērie extensão agroindustrial, 2)

FRANK, H. K. Importância das micotoxinas no preparo dos alimentos nos países tropicais. Boletim do Instituto de Tecnologia de Alimentos, Campinas, 56: 79-91, 1978. 
FRAYSSINET, C. \& LAFARGE, C. Action de l'aflatoxine sur la cellule hépatique du rat. Cahiers de Nutrition et de Dietêtique, Paris, 5 (2): 67-9, 1970.

GIBSON, W. W. C. Groundnut toxicity: Aspergillus blavus toxin (aflatoxin) in animal products. The Veterinary Record, London, 74 (32): 884, 1962.

GOLDBLATT, L. A. Control and removal of aflatoxin. Journal of the American Oil Chemists' Society, Chicago, 48 (10): $605-10,1971$.

GRAY, W. V. Groundnut toxicity. The Veterinary Record, London, 73 (35): 865, 1961 .

HAMSA, T.A. P. \& AYRES, J. C. Factors affecting aflatoxin contamination of cottonseed. I. Contamination of cottonseed with Aspergillus flavus at harvest and during storage. Journal of the American Oil Chemists' Society, Chicago, 54 (6): $219-24,1977$.

HARTLEY, R. D.; NESBITT, B. F.; O'KELLY, J. TOxic metabolites of Aspergillus flavus. Nature, London, 198 (4885): 10568, 1963.

HENDRICKSE, R. G.; COULTER, J. B. S.; LAMPLUGH, S. M.; MACFARTANE, S. B. J.; WILLIAMS, T. E.; OMER, M. I.A.; SULIMAN, G. I. Aflatoxins and kwashiorkor: a study in sudanese children. British Medical Journal, London, 285: 843-5, 1982.

HESSELTINE, C. W.; SHOTWELL, O. L.; ELIIS, J. J.; STUBBLEFIETD, R. D. Aflatoxin formation by Aspergillus flavus. Bacteriology Reviews, 30 (4): 795-805, 1966. 
KIYOMOTO, R. K. \& ASHWORTH JUNIOR; L. J. States of cotton boll rot in the San Joaquim Valley of California following simulated pink bollworm injuriy. phytopathology, st. Paul, 64 (11): 259-60, 1974 。

KLICH, M. E. \& LEE, I. S. Seed viability and aflatoxin production in individual cottonseed naturally contarinated with Aspergillus flavus. Journal of the American OiI Chemists' Society, Chicago, 59 (12): 545, 1982 .

KOLTUN, S. P.; GARDNER JUNIOR, H. K。; DOLLEAR, F. G。; RAYNER, E. T. Physical properties and aflatoxin content of individual cateye fluorescent cottonseeds. Journal of the American 0il Chemists' Society, Chicaco, 51 (4): 178-80, 1974.

IAFONT, $\dot{\dot{P}}$. Mycotoxins et alimentation. Cahiers de Nutrition et de Dietétique, Paris, 5 (2): 45, 1970.

LANCASTER, M. C.; JENKINS, F. P.; PHILIP, M. J. Toxicity associated with certain samples of groundnuts. Nature, London, 192 (16): 1095-6, 1961 .

LAPA, M. A. G." Influência da aflatoxina B ${ }_{1}$ sobre a resposta metabólica à desnutrição proteica. São Paulo, 1983, 75 p. [Doutoramento - Faculdade de Ciências Farmacêuticas da USP].

LEE, L.S. \& CUCULLU, A. F. Aflatoxin-negative cottonseeds in bright, greenish yellow fluorescent seed locks. Journal of the American Oil Chemists' Society, Chicago, 55 (7): $591,1978$. 
LEE, L. S.; LEE JUNIOR, L。 V*; RUSSELL, T. E. Aflatoxin in Arizona cottonseed: field inoculation of bolls by Aspergillus flavus spores in wind-ariven soil. Journal of the American Oil Chemists' Society, Chicago, 63 (4): 530-2, 1986.

LEE, L. S. \& RUSSELL, T. E. Distribution of aflatoxin-containing cottonseed within intact locks. Journal of the American Oil Chemists' Society, Chicago, 58 (1): 27-9, 1981.

LEE, L. S.; YATSU, L. Y.; GOLDBLATT, L. A. Stable basic lead soaps of alpha-disubstituted carboxylic acids. Journal of the American Oil Chemists' Society, Chicago, 44 (5): $331-2,1967$.

LOOSMORE, R. M.; ALLCROFT, R.; TUTTON, E. A.; CARNAGHAN, R. B. A. The presence of aflatoxin in a sample of cottonseed cake. The Veterinary Record, London, 76 (2): 64-5, 1964 .

LOOSMORE, R. M. \& HARDING, J. D. J. A toxic factor in Brazilian groundnut causing liver damage in pigs. The Veterinary Record, London, 73 (49): 1362-4, 1961.

LUKEFAHR, M. "J. \& MARTIN, D. F. Evaluation of damage to lint and seed of cotton caused by the pink bollworm. Journal of Economic Entomology, Baltimore, 56 (5): 710-3, 1963.

MALLOZZI, M. A. B. Deteç̧ão de aflatoxina em rações animais. Sintese, Rio de Janeiro, 6: 20-30, 1984.

MANN, T. B. "Disease" of turkey poults. The Veterinary

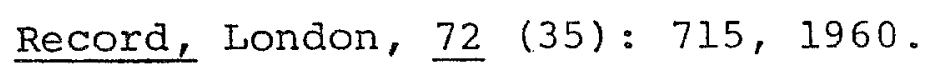


MARSH, P. B.; SIMPSON, M. E.; CPAIG, G, O.; DONOSO, I.;

RAPEY JUNIOR, H. H. Occurrence of aflatoxin in cottonseeds at harvest in relation to location of growth and field temperatures. Journal of Environmental Quality, Madison, $\underline{2}: 276-81,1973$.

MARSH, P. B. \& TAYLOR, E. E. The geographical distribution of fiber containing fluorescent spots associated with Aspergillus flavus in the United States cotton crop of 1957. The Plant Disease Reporter, Washington, 42: 136871,1958 .

MATTIL, K. F。; NORRIS, F. A.; STIRTON, A. J.; SWERN, D. Bailey's industrial oil and fat products. 3. ed. New York, Wiley, 1964. 1io3 p.

MAYNE, R:'Y.; PONS JUNIOR, W.A.; FRANZ JUNIOR, A. O.; GOLDBLATT, I. A. Elaboration of aflatoxin on cottonseed products by Aspergillus flavus. Journal of the American OiI Chemists' Society, Chicago, 43 (4): 251-3, 1966.

MCMEANS, J. L. \& ASHWORTH JUNIOR, L. J. Preharvest occurrence of Aspergillus flluus and aflatoxins in Califomia cottonseed. Phytopathology, St. Paul, 56 (8): 889, 1966.

i

MCMEANS, J. L.; ASHWORTH JUNIOR, L. J.; PONS JUNIOR, W. A. Aflatoxins in hull and meats of cottonseecs. Journal of the American Oil Chemists' Society; Chicago, 45 (8): $575-6,1968$.

MCMEANS, J. L. \& BROWN, C. M. Aflatoxins in cottonseed as affected by the pink bollworm: Crop Science, Macison, 15: 865-6, 1975 . 
MONCADA, F. R. \& GUTIERREZ; C. L. Harina de torta de algodão em formulaciones de algunos alimentos populares. Revista del Instituto de Investigaciones Tecnológicas, Bogotá, 118: $33-50,1979$.

MUSTAKAS, G. C.; GRIFEIN, E. L.; ALLEN, L. E.; SMITH, O. B. Production and nutritional avaliation. Journal of the American Oil Chemists' Society, Chicago, 4I (9): 607-14, 1964 .

MYCotoxINS and food safety. Food Technology, Chicag̣o, 40 (5): $59-66,1986$.

NAKAMURA, H. Aflatoxina. Boletim do Centro Tropical de Pesquisas e Tecnologia de Alimentos, Campinas, 15: 17-27, 1968.

NEWBERNE, P.M. Chronic aflatoxicosis. Journal of the American Veterinary Medical Association, Schaumburg, 163 (II) : $1262-7,1973$.

NORTHOLT, M. D. \& BULLERMAN, L, B. Prevention of mold growth and toxin production through control of environmental conditions". Journal of Food Protection, Ames, 45 (6): $519-26,1982$.

ORGANIZACION PANAMERICANA DE LA SALUD. Criterios de salud ambiental Il-micotoxinas. México, 1983. 131 p. (Publicaciön cientifica, 453)。

PIER, A. C. An overview of the mycotoxicoses of domestic animals. Journal of the American Veterinary Meaical Association, Schaumburg, 163 (11): 1259-61, 1973. 
PLATONOW, $N$. Effect of prolonged feeding of toxic groundnut meal in mice. The Veterinary Record, London, 76 (21): $589-90,1964$.

PONS JUNIOR, W. A.; CUCULLU, A. F。; FRANZ JUNIOR, A. O.; GOLDBLATT, L. A. Improved objective Eluorodensitometric determination of aflatoxins in cottonseed products. Journal of the American Oil Chemists' Society, Chicago, 45 (10): $694-9,1968$.

PONS JUNIOR, W. A.; CUCULLU, A. F.; LEE, L. S.; ROBERTSON, J . A.; FRANZ, A. O.; GOLDBLATT, L. A. Aflatoxins-determination of aflatoxins in agricultural products: use of aqueous acetone for extraction. Journal of the American Oil Chemists" Society, Chicago, 49 (3): 554-62, 1966 .

PONS JUNIOR, W. A.: LEE, L. S. \& SOTOLOFF, L. Revised method for aflatoxins in cottonseed products, and comparison of thin layer and high performance liquid chromatography determinative steps: collaborative study. Journal of the Association of Official Analytical Chemistry, Washington, $63(4): 889-906,1980$.

RICHMOND, J. W.; SUTCLIFFE, N. H.; DANIELS, N.W. R。; RUSSEIL EGGITT, P. W.; COPPOCK, J. B. M. Factors other than groundnut in the production of aflatoxin. The Veterinary Record, London, 74 (35): 962, 1962a.

RICHMOND, J.W.; SUTCLIFFE, N. H.; DANIELS, N.W. R.; RUSSEII EGGITT, P. W.; COPPOCK, J. B. M. Factors other than groundnut relating to "turkey $\mathrm{x}$ disease". The Veterinary Record, London, 14 (18): 544-5, $1962 \mathrm{~b}$. 
ROHR, R. Oleos e gorduras vegetais - seus subprociutos protëicos. 4. ed. Campinas, Funāação Tropical de Pesquisas e Tecnologia, 1978. $190 \mathrm{p}$.

RUSSELL, T.E. \& LEE, L。S. Effect of modular storage of Arizona seed cotton on levels of aflatoxins in seed. Journal of the American Oil Chemists' Society, Chicago, $\underline{62}(3): 515-7,1985$.

RUSSELI, T. E。; WATSON, T。 F。; RYAN, G. F。 Field accumulation of aflatoxin in cottonseed as influenced by irrigation termination cates and pink bollworm infestation. Applied and Environmental Microbiology, Washington, 31 (5): 711-3, 1976 .

SALUNKHE; D. K.; WU, M. T.; DO, J. Y。; MAAS, M. R. Mycotoxins in foods and feeds. In: GRAHAM, H. D. The safety of fooảs. 4. eả. Westport, AVI, 1982, p. 198-264.

SANDERS, T. H.; DÁVIS, N. D.; DIENER, U. L. Effects of carbon dioxide, temperature, and relative humidity on production of aflatoxin in peanuts. Journal of the American Oil Chemists' Society, Chicago, 45: 683-5, 1968.

SARGEANT, K。; O'KELLY, J.; CARNAGHAN; R. B. A.; ALLCROFT, R. The assay of a toxic principle in certain groundnut meals. The Veterinary Record, London, 73 (46): 1219-23, 1961.

SCHINDLER, A. F.; PALMER, J. G.; EISENBERG, W. V. Aflatoxin production by Aspergillus flavus as related to various temperatures. Applied Microbiology, Washington, 15 (5): 1006-9, 1967. 
SCHINDLER, A. F。; PALMER, J.G.; EISENBERG, W. V. Aflatoxin production by Aspergillus flavus at various temperatures. Phytopathology, St. Paul, 56 (8): 899, 1966.

SCHNEIDER, S.; LEON, R. de.; GARCIA-PRENDES, M.; ROLZ, C. Determination of aflatoxin and aflatoxin-producing cultures in recently ginned cottonseed in Central America. Journal of the American Oil Chemists' Society, Chicago, 49 (28): $700-1,1972$.

SCHROEDER, H。W. \& HEIN JUNIOR, H。 Effect of diumal temperature cycles on the production of aflatoxin. Applied Microbiology, Washington, 16 (7): 988-90, 1968.

SGARBIERI, V. C. Aflatoxinas - importância em tecnologia de alimentos e nutrição. Boletim do Centro Tropical de Pesquisas e Tecnologia de Alimentos, Campinas, 18: 23-82, 1969 .

SMITH, K. M. "Disease" of turkey noults. The Veterinary Record, London, 72 (32): 652, 1960 .

SPORN, M. B.; DINGMAN, C. W.; PHELPS, H. I.; WOGAN, G. N. Aflatoxin"B ${ }_{1}$ : binding to DNA in vitro and alteration of RNA metabolism in vivo. Science, Washington, 151 (3717): $1539-41,1966$.

STEVENS, A. J.; SAUNDERS, C. N.; SPENCE; J. B.; NEWNHAM, A. G. Investigations into "disease" of turkey poults. The Veterinary Record, London, 72 (31): 627-8, 1960.

STOLOFF, I. Aflatoxin control; past and present. Journal of the Association of Official Analytical Chemistry, Washington, 63 (5): 1067, 73, 1980 . 
SWARBRICK, $O$. Disease of turkey poults. The Veterinary Record, London, 72 (33): 671, 1960.

TAFURI, M. L. \& RODRIGUES, M. T. Subprodutos das indústrias de óleos na alimentação animal. Informe Agropecuário, Belo Horizonte, 10 (119): 43-8, 1984.

TANGo, J. S. Aflatoxina. Boletim do Instituto de Tecnologia de Alimentos, Campinas, 37: 37-95, 1974.

TANGo, J.S. Industrialização do caroço de algodão e dos seus produtos. Boletim do Centro Tropical de Pesquisas e Tecnologia de Alimentos, Campinas, 4 : 1-19, 1965; Tecnologia de Alimentos e Bebidas, São Paulo, 2 (1): 23-33, 1966.

TANGO, J. S. Gossipol. Boletim do Instituto de Tecnologia de Alimentos, Campinas, 34: 1-31, 1973.

TROPICAL RRODUCTS INSTITUTE. A method for the detection of aflatoxin in groundnuts and groundnut products. London, TPI, 1962. 01 p. (TPI Report, 30)

VELASCO, J.; WḦITAKER, T. B.; WHITTEN, M. E. Sampling : cottonseed lots for aflatoxin contamination. Journal of the American Oil Chemists' Society, Chicago, 52 (6): 1915,1975 .

WANNOP, C. C. Disease of turkey poults. The Veterinary Record, Lonaion, $\underline{72}$ (33): 671-2, 1960.

WESSEL, J. R. \& STOLOFF, B. S. Regulatory surveillance for aflatoxin and other mycotoxins in feeds, meat, and milk. Journal of the American Veterinary Medical Association, Schaumburg, 163 (11): 1284-7, 1973. 
WHITTEN, M. E。 \& SMITH, L。 L, Effect of storage conditions on increase in aflatoxins in cottonseed: a small lot study. Journal of the American Oil Chemists' Society, Chicago, 49 (10): 596-7, 1972 .

WIDSTROM, N. W. The role of insects and other plant pests in aflatoxin contamination of corn, cotton and peanuts - a review. Journal of Environmental Quality, Madison, 8 (1): 5-11, 1979 .

WOGAN, G. N. Aflatoxin risks and control measures. Federation Proceedings, Bethesda, 27 (8): 932-8, 1968.

WOGAN, G. N. Chemical nature and biological effects of the aflatoxins. Bacteriological Reviews, Washington, 30 (2): $460-70,1966$. 